UNIVERSITY OF WAIKATO

Hamilton

New Zealand

\title{
Classic and Spatial Shift-Share Analysis of State-Level Employment Change in Brazil
}

Valente J. Matlaba, Mark Holmes, Philip McCann and Jacques Poot

\section{Department of Economics}

Working Paper in Economics 08/12

\author{
July 2012 \\ Corresponding Author \\ Valente Matlaba \\ Economics Department \\ University of Waikato \\ Private Bag 3105 \\ Hamilton, New Zealand \\ Email: valente.matlaba@yahoo.com.br \\ Mark Holmes \\ Economics Department, University of Waikato \\ Email: holmesmj@waikato.ac.nz \\ Philip McCann \\ Department of Economic Geography, University of Groningen \\ Email: p.mccann@rug.nl \\ Jacques Poot \\ National Institute of Demographic and Economic Analysis \\ University of Waikato \\ Email: jpoot@waikato.ac.nz
}




\begin{abstract}
This paper combines classic and spatial shift-share decompositions of 1981 to 2006 employment change across the 27 states of Brazil. The classic shift-share method shows higher employment growth rates for underdeveloped regions that are due to an advantageous industry-mix and also due to additional job creation, commonly referred to as the competitive effect. Alternative decompositions proposed in the literature do not change this broad conclusion. Further examination employing exploratory spatial data analysis (ESDA) shows spatial correlation of both the industry-mix and the competitive effects. Considering that until the 1960s economic activities were more concentrated in southern regions of Brazil than they are nowadays, these results support beta convergence theories but also find evidence of agglomeration effects. Additionally, a very simple spatial decomposition is proposed that accounts for the spatially-weighted growth of surrounding states. Favourable growth in northern and centre-western states is basically associated with those states' strengths in potential spatial spillover effect and in spatial competitive effect.
\end{abstract}

\title{
JEL Classification
}

J21; O18; N66; R11

\section{Keywords}

regional employment

shift-share analysis

spatial autocorrelation

spatial spillovers

Brazil

\section{Acknowledgements}

We thank Bill Cochrane for advice on computational aspects of our project. 


\section{Introduction}

The Brazilian economy has gone through a remarkable transformation since the difficult times of the last quarter of the $20^{\text {th }}$ century. Brazil is now seen as one of the engines of global economic growth and together with Russia, India and China making up the often cited BRIC acronym. During the next decade, Brazil is expected to overtake Britain and France and become the world's fifth largest economy, with São Paulo possibly the world's fifth wealthiest city (The Economist, 2009).

Such rapid national development begs the question of whether the benefits are being reaped in all regions, with poorer ones catching up, or whether the gap between the rich and poor regions is widening. At present, Gross State Product (GSP) per capita in Rio de Janeiro and São Paulo is 50 percent higher than Brazil's Gross Domestic Product (GDP) per capita, but in the northeastern states of Piaui and Maranhão, GSP per capita is less than 30 percent of Brazil's GDP per capita.

To address such a question one would ideally carry out a formal econometric analysis along the lines of neoclassical or endogenous growth models (e.g. Barro and Sala-i-Martin, 2004). Alternatively, one might consider the dynamic adjustments suggested by models of the New Economic Geography (e.g. Brakman et al., 2001). In either case, a first requirement is the availability of reliable regional accounts data at sectoral and aggregate levels, plus a range of socio-economic indicators. In Brazil such subnational accounts data have been, until recently, rather incomplete or difficult to compare over time.

However, sub-national demographic and employment data are available on a consistent basis for several decades. In another paper (Matlaba et al, 2010), we exploited such data to identify the impact of Marshall-Arrow-Romer, Porter and Jacobs' externalities in manufacturing by means of the Glaeser et al. (1992) approach. Here a broader approach to analyse state growth in Brazil involves considering all production sectors simultaneously. For this purpose this paper starts with the conventional shift-share accounting framework, which decomposes total growth in a region in terms of national, industry-mix, and competitive shift effects (Dunn, 1960; Esteban-Marquillas, 1972; Arcelus, 1984; Berzeg, 1978, 1984; Haynes and Machunda, 1987; Dinc, Haynes and Qiangsheng, 1998; Dinc and Haynes, 1999). Despite criticisms and various alternative formulations, the classic shift-share approach remains popular after half a century of application (Knudsen and Barff, 1991; Hoppes, 1991; McDonough and Sihag, 1991; Loveridge, 1995; Knudsen, 2000; Shields, 2003).

This approach is extended in this paper in five ways. First, we tracked the classic shiftshare components over five consecutive quinquennia, starting in 1981. This provides a dynamic perspective on the shift-share decomposition. Secondly, we defined and calculated a new structural change effect to show that most states have been creating jobs in industries that nationally became more prominent and shed jobs in industries that contracted nationally, i.e. states generally did not go against the trends. Thirdly, we calculated a wide range of alternative shift-share decompositions proposed in the literature to show that these 
refinements lead to interpretations that remain very similar to those of classic shift-share analysis. Fourthly, we identified the spatial patterns in the shift-share decomposition by means of exploratory spatial data analysis (ESDA). Fifthly, we used Nazara and Hewings's (2004) spatial shift-share taxonomy to add a spatial component for each state into the shiftshare decomposition, namely a measure of spatially weighted employment growth in surrounding states. Nazara and Hewings also introduce additional industry-specific spatial components into shift-share, but because the focus of this paper is on regional aggregates rather than individual industries, the latter spatial shift-share taxonomy can be simplified to a four-component decomposition. In this decomposition, the spatial component has an intuitively attractive interpretation, namely the regional rate of growth one might expect in the presence of full spatial spillover of growth in surrounding regions, after controlling for national industry-specific growth. Nazara and Hewings refer to this effect as (minus) the neighbour-nation regional shift effect.

Together with the classic shift-share decomposition, the spatial analysis provides evidence of a catching up of peripheral regions in Brazil, although agglomeration effects ensure that the dominance of the states of the south east remains. The results of this dynamic and spatial shift-share analysis are therefore consistent with those of the econometric literature on regional development in Brazil (see e.g. Rolim, 2008; Daumal and Zignago, 2010).

The period under consideration is 1981 to 2006. The reasons for the choice of this period are twofold. First, the available sub-national data are only complete and consistent for this period only. Secondly, this period covers a wide range of socio-economic and political conditions in Brazilian economic history: economically, it includes sub-periods of depression (1981-1983; 1986-1993) and prosperity (1984-1985; 1994-2006); politically, it includes dictatorship (1981-1984), democracy (1990-2006), and a combination of both regimes (19851989); institutionally, in addition to political changes themselves, it presents a sub-period of a relatively closed economy from 1981 to 1989 and another of a gradual trade liberalisation since 1989 (Lobo, 1996; Abreu, 2008a, 2008b; Abreu and Werneck, 2008). Interestingly, it will be seen later in this paper that the fundamental driving forces of growth (or decline) as measured by dynamic spatial shift-share analysis remain robust under such dramatically changing circumstances.

Previous shift-share studies of growth in various countries often only consider nonspatial effects (e.g. Haynes and Dinc, 1997; Keil, 1992; Hoppes, 1991; Barff and Knight, 1988; Blien and Wolf, 2002). ${ }^{1}$ This is also the case for Brazil (Rolim, 2008; Nogueira and Lopes, 2008; Chahad et al., 2002; Amorim and Da Mata, 2008). Some studies incorporate in the shift-share method the implications of international trade for the regional economy (Markusen et al., 1991; Noponen et al., 1998; Gazel and Schwer, 1998; Dinc and Haynes, 2005; Fotopoulos et al., 2010), but the analysis is not developed in that direction in this paper,

1 However, Le Gallo and Kamarianakis (2010) combine Exploratory Spatial Data Analysis (ESDA) tools with spatial seemingly unrelated regressions (SUR) modelling to explain productivity disparities across European regions from 1975 to 2002. 
given that Brazil's international trade accounted over the period considered for no more than 24 percent of GDP (and was in fact 60 years earlier higher than during the 1981-2006 period). Instead, this paper integrates the non-spatial classic shift-share methodology (Andrikopoulos et al, 1990; Selting and Loveridge, 1994; Ray and Harvey, 1995; Yasin et al., 2010) with Exploratory Spatial Data Analysis (ESDA) of the Shift-Share Components (Cochrane and Poot, 2008) and the methodology developed in Nazara and Hewings (2004), which explicitly incorporates spatial effects in the shift-share taxonomy to explain growth of regions. $^{2}$

The paper is organised as follows. Section 2 briefly presents the classic shift-share methodology. Section 3 describes the employment data used and their sources. Section 4 summarises the main facts of the Brazilian economy since 1981 and presents the results of the classic shift-share. Section 5 analyses structural change in Brazil in terms of the shiftshare components. Section 6 presents alternative shift-share formulations. Section 7 performs exploratory spatial data analysis (ESDA) for industry-mix and competitive effect components of the classic shift-share method. Section 8 provides simple spatial shift-share decomposition, building on Nazara and Hewings (2004). Finally, section 9 provides concluding remarks.

\section{Classic Multi-Period Shift-Share Analysis}

This section briefly presents the classic shift-share method. This method decomposes the change in employment as follows (e.g., Cochrane and Poot, 2008, p. 55):

$\Delta E_{i r}^{t} \equiv E_{i r}^{t}-E_{i r}^{t-1} \equiv N E_{i r}^{t}+I M_{i r}^{t}+C E_{i r}^{t}$

where:

$$
\begin{aligned}
& N E_{i r}^{t}=g_{00}^{t} \times E_{i r}^{t-1} \\
& I M_{i r}^{t}=\left(g_{i 0}^{t}-g_{00}^{t}\right) \times E_{i r}^{t-1} \\
& C E_{i r}^{t}=\left(g_{i r}^{t}-g_{i 0}^{t}\right) \times E_{i r}^{t-1}
\end{aligned}
$$

The terms in the above equations are defined as:

$E_{\text {ir }}^{t-1}=$ Employment in the $i^{\text {th }}$ industry in the $r^{\text {th }}$ region at time $t-1$.

$E_{i r}^{t}=$ Employment in the $i^{t h}$ industry in the $r^{\text {th }}$ region at time $t$.

$N E_{i r}^{t}=$ National Growth Effect on industry $i$ in the $r^{\text {th }}$ region between $(t-1)$ and $t$.

$I M_{i r}^{t}=$ Industry-Mix Effect on industry $i$ in the $r^{\text {th }}$ region between $(t-1)$ and $t$.

$C E_{\text {ir }}^{t}=$ Competitive Effect on industry $i$ in the $r^{\text {th }}$ region between $(t-1)$ and $t$.

$g_{i r}^{t}=$ Growth rate of employment in industry $i$ and region $r$ between $(t-1)$ and $t$.

$g_{i 0}^{t}=$ Growth rate of nationwide employment in industry $i$ between $(t-1)$ and $t$.

$g_{00}^{t}=$ Growth rate in nationwide total employment between $(t-1)$ and $t$.

2 Mitchell et al. (2005) apply Nazara and Hewings's (2004) spatial shift-share decomposition to data on Australian regions. Mayor \& López (2008) combined a variety of spatial analysis tools with the shift-share method. 
Using (1) to (4) if we aggregate employment in each region $r$ over industries $i$ and define $g_{0 r}^{t}$ as the growth rate of total employment in region $r$ between times $(t-1)$ and $t$, this growth rate can be decomposed into a national growth rate; a growth rate due to the industrymix and a residual that is referred to as the competitive growth rate $c_{0 r}^{t}$. Hence,

$g_{0 r}^{t} \equiv g_{00}^{t}+m_{0 r}^{t}+c_{0 r}^{t}$

in which the growth component due to industry-mix is defined by

$m_{0 r}^{t} \equiv \sum_{i} w_{i r}^{t-1}\left(g_{i 0}^{t}-g_{00}^{t}\right)$

with $w_{i r}^{t-1}$ the fraction of employment in region $r$ that is in industry $i$ at time $(t-1)$. Equation (6) shows that the industry-mix growth rate is a weighted average of national sectoral growth rates, minus national aggregate growth, with the weights being the shares of the various sectors in regional employment at the beginning of the period under consideration.

\section{Data and Sources}

This paper uses employment data from IPEA - Institute of Applied Economic Research (www.ipea.gov.br). IPEA is one of the official public data sources in Brazil and it presents a variety of socio-economic data collected from public and private institutions, mostly at the state level.

Data have been collected for all 27 states (including Distrito Federal; for states' boundaries. See Figure 1) from which information on the number of employed people in each state by sector was extracted from 1981 to 2006. These sectors are: (1) agriculture and fishing; (2) commerce; (3) construction; (4) electricity, water and gas; (5) finance; (6) manufacturing; (7) mining; (8) services and (9) transportation and communications. State sectoral employment was calculated by multiplying the reported percentage of employed people in each sector by reported total employment in each state.

The five selected periods to analyse employment growth are: 1981-1986, 1986-1991, 1991-1996, 1996-2001, and 2001-2006. Although there are data to calculate annual changes, the use of five-year periods provides some control for cyclical employment fluctuations, as suggested by Thirlwall (1967) (see Barff and Knight, 1988, pp. 3-4). Using periods of equal duration addresses Brown's (1969) criticism that varying the periods may lead to the risk of an undue influence of sudden employment (or income) changes in atypical years (Barff and Knight, 1988, p. 6; Knudsen and Barff, 1991, pp. 427-428; Knudsen, 2000, pp. 179-180).

There are missing employment data for all states in 1991. To address this problem, we simply interpolated the distribution of employment across sectors between 1990 and 1992 and we subsequently applied the interpolated shares to the known state total employment. Additionally, there were missing employment data for Tocantins from 1981 to 1991. Here we 
assumed that total employment growth was identical to known state population growth over the sub-periods 1981-86, 1986-91, and 1991-96. We assumed sectoral shares in Tocantins to have been the same in 1981, 1986, and 1991 as observed in $1996{ }^{3}$

Figure 1: Brazil’s States Boundaries - 26 States plus Distrito Federal

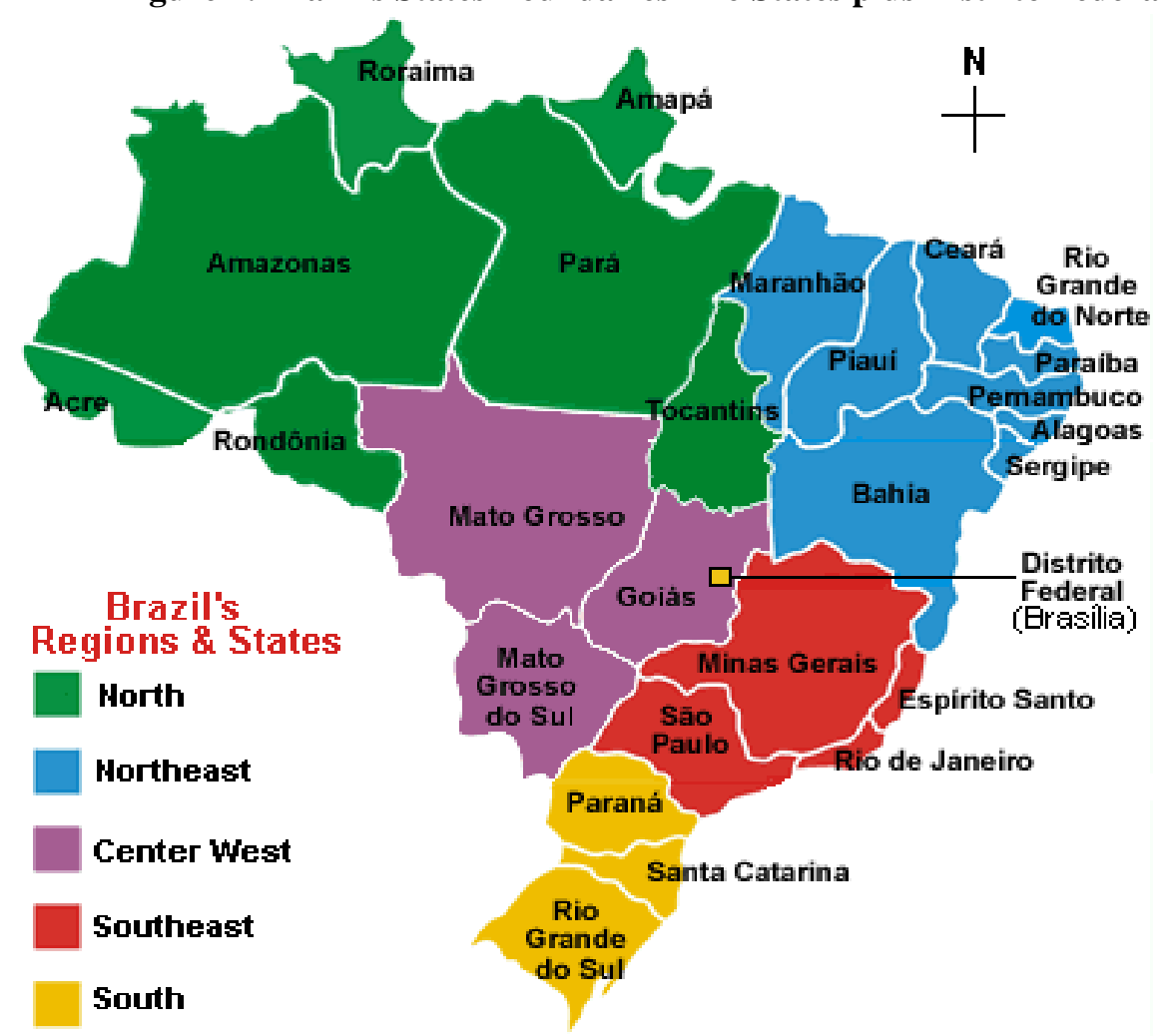

Source: http://www.brazilmycountry.com/brazil-map.html\#regions\%20map

\section{Results of Classic Shift-Share Analysis}

This section outlines the main characteristics of the events that shaped the performance of the Brazilian economy from 1981 to 2006; then, using employment data, it presents the results of the non-spatial shift-share analysis (Tables 1 to 3 ). In terms of the economic history of Brazil, 1981-2006 can be subdivided into three periods as follows.

Period I: 1981-1984 (the final part of the dictatorship or 'Authoritarian State' period, which started in 1964). The main characteristics are (Lobo, 1996; Fausto, 1999; Abreu, 2008a): i) the combination of economic stagnation and inflation ('stagflation'); ii) little political rights and freedom; iii) oil shocks (1974-1980) causing macroeconomic instability;

3 An alternative assumption would have been to backcast the 1981-1991 Tocantins sectoral shares from 1996 by means of the observed trends in national sectoral shares. This has very little impact on the results reported in the tables in this paper. 
iv) economic redistribution that harmed the northeast and benefited the middle-west, north and south regions; v) protectionism, contractionist policies, and falling output (1981-1983).

Period II: 1985-1989 (democratic transition). This period is characterised by poor economic performance as a result of hyperinflation and stagnation.

Period III: 1989-2006 (Trade liberalisation and the return to democracy). The main facts are (Lobo, 1996; Abreu, 2008b; Abreu and Werneck, 2008): i) the structural reforms under Collor de Mello (1990-1992) and Itamar Franco (1992-1994) presidencies; ii) the policies that aimed to reduce and stabilise inflation and unemployment were more successful after mid-1994; however, iii) as Abreu and Werneck (2008, p. 432) point out, '(...) between 1994 and 2004 per capita GDP (gross domestic product) increased [at] an average of only 0.9 percent per annum'.

Summarising economic growth over the 1981-2006 period, Abreu (2008b, p. 395) states:

In the years 1981-1983, during the administration of General João Figueiredo (19791985), the last of five successive military presidents since the military coup of 1964, there was a sharp deterioration in the Brazilian GDP growth performance. Brazil suffered its most severe recession of the twentieth century. GDP fell 4.9 percent from its pick in 1980. After a brief recovery in 1984-1985 when GDP grew on average 7 percent per annum - years that also witnessed a transition from military to civilian rule (and ultimately a fully fledged democracy) - growth performance remained mediocre during the following decades. Between 1981 and 1994 GDP per capita increased on average less than 0.1 percent annually. And there was only limited improvement in the decade after 1994. (Bolds added)

Table 1: National Employment by Sector, 1981-2006

\begin{tabular}{|c|c|c|c|c|c|c|}
\hline & $\begin{array}{c}\text { \% shares and } \\
\text { total } 1981\end{array}$ & $\begin{array}{c}\text { 1981-86 } \\
\text { change (\%) }\end{array}$ & $\begin{array}{c}\text { 1986-91 } \\
\text { change (\%) }\end{array}$ & $\begin{array}{c}\text { 1991-96 } \\
\text { change (\%) }\end{array}$ & $\begin{array}{c}\text { 1996-01 } \\
\text { change (\%) }\end{array}$ & $\begin{array}{c}\text { 2001-06 } \\
\text { change (\%) }\end{array}$ \\
\hline Agriculture and Fishing & 32.2 & 5.7 & 13.1 & 2.0 & -5.0 & 10.6 \\
\hline Commerce & 11.2 & 29.8 & 28.1 & 15.8 & 19.6 & 44.4 \\
\hline Construction & 8.7 & -4.9 & 9.9 & 13.4 & 14.4 & 17.6 \\
\hline Electricity, Water and Gas & 0.8 & 9.5 & 4.5 & -8.7 & -2.7 & 18.3 \\
\hline Financial Sector & 2.1 & 20.1 & -3.2 & -20.1 & -1.9 & 127.5 \\
\hline Mining & 0.6 & 40.5 & -5.0 & -40.8 & 22.8 & 46.3 \\
\hline Services & 24.6 & 30.8 & 26.5 & 20.4 & 19.2 & 23.2 \\
\hline Transportation and Communications & 4.3 & 9.7 & 20.5 & 11.1 & 24.6 & 22.8 \\
\hline National Employment & $41,397,661$ & 17.7 & 16.2 & 9.1 & 11.1 & 26.5 \\
\hline
\end{tabular}

Notes: The estimate of the National Population for 1981 is 122,500,000 inhabitants (estimate based on interpolation from IBGE - Brazilian Institute of Geography and Statistics population census data). The average annual GDP per capita growth rate from 1981 to 2006 is $4.1 \%$. 
A comparison of national and sectoral employment growth between the five-year subperiods show that the periods 1981-1986 and 1996-2001 stand out, and productivity declined even though employment increased. Commerce, financial sector, services, and transportation and communications are industries that had significant employment growth throughout the 1981-2006 period (when considering a five-year sub-periods average growth of at least 17.8 percent). Employment change was rather volatile in the other sectors.

Table 2 provides the classic shift-share decomposition of total employment growth in Brazil's states in terms of the national, industry-mix and competitive components for the five sub-periods. The states have been ranked according to the five-period average total employment growth rate (from high to low). Roraima had the highest average five-year growth rate (75.1 percent) and Rio de Janeiro the lowest (10.9 percent).

The ranking is consistent with the finding of long-run regional convergence already elaborated in Matlaba (2012, chapters 3 and 4). Matlaba (2012, chapter 3) concluded that in particular specialisation has been responsible for regional convergence. The observed convergence is a result of a reduction in concentration of economic activities that essentially benefited middle-west and north Brazil, rather than the traditional large markets of São Paulo and Rio de Janeiro ${ }^{4}$. This can be seen from two features in Table 2. First, the top ten states in terms of total employment growth are in all five-year sub-periods either from north or middle-west regions. The only other states that 'infiltrated' the top ten in the ranking are Rio Grande do Norte in the 1981-1986 and 1986-1991 periods; Maranhão, Piauí, Sergipe, Paraíba, and Ceará in 1991-1996; Alagoas in 1996-2001; and Sergipe and Paraíba in 20012006. All these states are from the northeast region, which is contiguous to the north and middle-west regions. In the five-period averages from 1981 to 2006, Brazil’s richest states of São Paulo and Rio de Janeiro occupied the lower end of the employment growth ranking. These two states were $23^{\text {rd }}$ and $27^{\text {th }}$ respectively.

Table 3 shows state Location Quotients (hereafter LQ). LQ $<1$ indicates that the area is less specialised than the nation in a particular sector; LQ>1 means the area is highly specialised in a specific sector. Based on tables 2 and 3, three main questions are addressed.

The first question is to identify the states that have a high competitive growth rate (Table 2) and to check how this is linked to the LQ (Table 3). The north and middle-west states occupied the top nine positions in competitiveness. ${ }^{5}$ Their positive competitive effect

4 Chahad, Comune, and Haddad (2002) found a similar result when analysing employment change from 1985 to 1997 in Brazil. However, such findings contradict previous studies for the period 1960-1970 in which centripetal forces were apparently stronger than centrifugal forces, with high growth of the number of firms, the number of people employed, and gross value of production in the main metropolitan centres (Sao Paulo and Rio de Janeiro or former Guanabara) (Enders, 1980). By comparison, Fotopoulos \& Spence (1999, p. 1737), analysing a change of manufacturing industry establishments from 1984 to 1988 in Greece, found an outward movement of manufacturing plants from Central Greece and Athens (the largest markets in Greece). Another comparison is proved by Hanham and Banasick (2000, pp. 110-111) who cite Edgington (1994) who found that the peripheral regions of the north and south of Japan have had faster manufacturing employment growth during the 1980s than the metropolitan regions of central Japan.

5 While the middle-west states of Goiás and Mato Grosso do Sul are not in this list, the competitiveness component in the latter state is closer to that of the group. 
suggests that their sectoral employment grew generally above national sectoral employment. ${ }^{6}$ However, this effect decreased for most of these states, and eight of the other states, from the first to the second sub-period and this amplified in the third and the fourth sub-periods. However, the competitive effect recuperated over the last sub-period. ${ }^{7}$ The behaviour of the competitive effect in the last sub-period is consistent with the successful policies to control inflation and reduce unemployment in the trade liberalisation period. The impact of policies was properly captured by the observed national effect in Table 2 which has a minimum in the third sub-period, even though there is a caveat that the stabilisation policies have benefited the northern and middle-west states rather more than the whole nation (see states with the lowest levels in competitive effect and those with a negative competitive effect in Table 2 for the last two sub-periods). This result may be interpreted as positive as it shows a process of employment deconcentration across states.

The analysis of the LQs in Table 3 indicates that the most competitive states, due to specialisation (with an LQ higher than 1.5) in faster growth industries nationwide, are basically located in the north and middle-west regions. ${ }^{8}$ One of the reasons for the dominance of these two regions is that, being historically lagged regions, the development of infrastructure helped boost employment in all sectors over the study period. ${ }^{9}$ Considering the first sub-period, there are five sectors (out of nine) that grew fast with a growth rate of at least 20 percent nationally. Among these five sectors, northern and middle-west states have a LQ greater than 1.5 in three sectors, such as commerce, mining and services. On the other hand, São Paulo and Rio de Janeiro accounted for most national employment in the financial sector and manufacturing. These two sectors, however, experienced weak growth between the second and fourth sub-periods (in the third sub-period both even had negative growth rates) before they recovered in the last sub-period due to successful policies implemented in this sub-period.

Based on the 1981-1986 sub-period, Table 2 suggests that there are some other competitive states, such as Espirito Santo, Santa Catarina, Ceará, Minas Gerais, Alagoas, Maranhão, Paraíba and Bahia. However, all but one of these states had a negative competitive effect for at least two of the sub-periods. According to LQs in Table 3, these states are relatively specialised in the following sectors, with an LQ of at least 1.40: agriculture and fishing (Espírito Santo, Santa Catarina, Minas Gerais, Alagoas, Maranhão, and Bahia), construction (Ceará and Paraíba), electricity, water and gas, and manufacturing (Santa Catarina), and mining (Espírito Santo and Bahia).

6 Except: Tocantins in the 1986-1991 period; Rondônia and Distrito Federal in the 1991-1996 period; and Mato Grosso in the 2001-2006.

7 The average competitive effect across all states is as follows: 1981-1986: 18.4 percent; 1986-1991: 8.7 percent; 1991-1996: 8.6 percent; 1996-2001: 6 percent; and 2001-2006: 16.3 percent.

8 Although, overall, the northern states were the less specialised and Table 2 shows that they had the lowest Hirschman-Herfindahl Index in 1981.

9 It is worth noting that in 1981 Roraima had an LQ of 1.54 for commerce, 2.33 for construction, 3.7 for electricity, water and gas, 1.38 for financial sector, 0.37 for manufacturing, 8.42 for mining, 1.28 for services, and 1.58 for transportation and communication. This state had the highest annual average growth rate (11.25 percent) for manufacturing industry employment from 1981 to 2006. 
The second question is whether the observed total regional employment growth rates in Table 2 are consistent with the earlier described economic history of Brazil. Table 2 indicates that, as expected, the core regions of southeast and south had generally lower employment growth rates than the lagging north and middle-west and some northeast states. This trend is compatible with high specialisation of the lagging regions for three (out of five) of the faster growing sectors of economic activity in Brazil. ${ }^{10}$

The third issue is whether the differences in total state employment growth rates are due to differences in industry-mix at the state level relative to the national economy or whether these differences are due to the competitive advantage that a specific state has relative to the national economy. Table 2 shows that the top six (out of 27) states - in terms of the five-period average employment growth rates - are the only states that have had a positive industry-mix effect in five-year periods. ${ }^{11}$ Again, these states are either from the north or the middle-west regions of Brazil and appear to have had an industry structure that has been more beneficial than that of the other states, even during periods in which, for some sectors, the nation's sectoral growth rate was less than average growth. Additionally, these top six states had the highest competitive effect over time as a result of a high LQ in six (out of nine) sectors in 1981 (see Table 3) and specialisation in sectors with a growth rate larger than that observed for the nation. These sectors are: commerce, services, and transportation and communication in the first period; construction and services in the second period; services in the third and the fourth periods; and, finally, commerce and services in the fifth period.

Tables 2 and 3

(At end of paper)

Conversely, 16 of the other states had a negative five-period industry-mix average as a result of a highly negative industry-mix component at least in one of the five-year subperiods. This finding indicates that, with respect to the five-period average, these 16 states were more harmed by the national poor performance through following the nation's trend in the sub-periods in which the nation had a negative (or low positive) sectoral employment growth rate, because they were endowed with industries that were growing less than average. It is not a surprise that those 16 states also had the smallest (even negative) competitive average effect over the study period.

10 Among the other four sectors, the three sectors in which north and middle-west had a comparative disadvantage are agriculture \& fishing, manufacturing, and financial sector. These latter two sectors had some of the highest growth rates in the sub-period 2001-2006, 127.5 percent and 38.6 percent, respectively (see Table 1).

11 Excluding Rio de Janeiro, which had a positive industry-mix effect in all of the five-year periods, but had the lowest five-period average total employment growth due to a consistently high negative competitive effect. 


\section{Structural Change}

This section and the next two replicate for Brazil Cochrane and Poot's (2008) shift-share analysis of employment change in New Zealand. This section investigates whether states sectoral growth rates followed the national trend. The approach to answer this question is to decompose the industry-mix effect from equation (6) in section 2 as follows:

$$
\sum_{i} w_{i r}^{t-1}\left(g_{i 0}^{t}-g_{00}^{t}\right) \equiv \sum_{i} w_{i r}^{t}\left(g_{i 0}^{t}-g_{00}^{t}\right)+\sum_{i}\left(w_{i r}^{t-1}-w_{i r}^{t}\right)\left(g_{i 0}^{t}-g_{00}^{t}\right)
$$

The second term of the right-hand side of the equation above measures the effect of changing industry composition on the regional employment growth rate. This will be referred to as the structural change effect. The industry-mix effect calculated by means of end-of-the period weights will be referred to as the modified industry-mix effect.

The states among the top ten in terms of the total employment growth rate (see Table 2) also have the highest (positive) all five-year periods average for the modified industry-mix effect (Table 4). These states are: Acre, Amazonas, Amapá, Pará, Rondônia, and Roraima from the north region and Distrito Federal, Goiás, and Mato Grosso do Sul from the middlewest region. Rio de Janeiro and São Paulo now have a modified industry-mix effect at levels comparable to those of northern and middle-west states. As shown earlier, northern and middle-west states benefited from growth in sectors in which they were highly specialised (three out of nine) in 1981, even though that growth was larger in some sectors than others depending on the period (Table 1). In terms of magnitude, the average modified industry-mix effect in Brazil as a whole was largest for 1986-1991 and smallest for the 2001-2006 period.

The structural effect is negative in all but eight cases (Acre, 1996-2001 and 2001-2006; Amazonas, 2001-2006; Amapá, 1986-1991, 1991-1996 and 2001-2006; Pará, 2001-2006; Rondônia and Roraima, 1996-2001 and 2001-2006; Tocantins, 1986-1991; and Alagoas, 1996-2001). The former seven states are in the north, while the latter is in the northeast region. This indicates that the sectoral trends in those eight states were different from the nation in the specified periods. However, given that the number of these cases is small, the overall conclusion is that most states have generally not gone against the national trend in terms of structural change. Hence, when a sector grows faster (slower) than average, its share in employment increases (decreases) in almost all regions. The positive structural change effects occur predominantly in the fourth and fifth five-year periods. These represent a period of a relative prosperity in terms of Brazil's GDP per capita increase, although the fourth subperiod is worse than the fifth. In the last period only the northern states (six out of seven) have gone against the national trend (i.e. had a positive sign in structural change effect). 
Table 4: The Modified Industry-Mix and Structural Change Effects on Employment Growth in Brazil

\begin{tabular}{|c|c|c|c|c|c|c|c|c|c|c|}
\hline \multirow[b]{2}{*}{ State** } & \multicolumn{5}{|c|}{ Modified Industry Mix Effect } & \multicolumn{5}{|c|}{ Structural Change Effect } \\
\hline & $\begin{array}{c}1981- \\
86\end{array}$ & $\begin{array}{c}1986- \\
91\end{array}$ & $\begin{array}{c}1991- \\
96\end{array}$ & $\begin{array}{c}1996- \\
01\end{array}$ & $\begin{array}{c}2001- \\
06\end{array}$ & $\begin{array}{c}1981- \\
86\end{array}$ & $\begin{array}{c}1986- \\
91\end{array}$ & $\begin{array}{c}1991- \\
96\end{array}$ & $\begin{array}{c}1996- \\
01\end{array}$ & $\begin{array}{c}2001- \\
06\end{array}$ \\
\hline Acre & 6.91 & 4.48 & 4.80 & 3.05 & -2.82 & -1.43 & -0.09 & -1.01 & 1.90 & 2.81 \\
\hline Amazonas & 5.13 & 1.67 & 2.63 & 4.25 & 0.83 & -0.31 & -1.74 & -1.14 & -0.84 & 2.15 \\
\hline Amapá & 6.06 & 4.88 & 4.02 & 6.27 & 1.58 & -1.82 & 0.20 & 0.85 & -2.62 & 0.80 \\
\hline Pará & 5.05 & 3.77 & 3.30 & 3.68 & 1.93 & -1.03 & -0.82 & -0.68 & -0.71 & 0.15 \\
\hline Rondônia & 4.88 & 3.55 & 2.64 & 3.27 & -2.40 & -1.63 & -0.64 & -0.26 & 0.65 & 3.40 \\
\hline Roraima & 5.65 & 3.43 & 4.98 & 4.03 & -1.45 & -4.00 & -0.25 & -2.28 & 0.93 & 1.42 \\
\hline Tocantins & -6.93 & -0.20 & 0.67 & -2.01 & -2.02 & -0.27 & 0.46 & -4.63 & -1.17 & -2.72 \\
\hline Alagoas & -4.00 & 0.30 & -0.65 & -4.12 & -3.97 & -0.60 & -1.26 & -0.79 & 0.55 & -1.55 \\
\hline Bahia & -3.44 & 0.75 & -0.46 & -2.78 & -2.89 & -0.78 & -0.81 & -0.67 & -1.01 & -1.57 \\
\hline Ceará & -0.34 & 0.73 & -0.41 & -1.22 & -0.43 & -2.65 & -1.18 & -0.16 & -2.12 & -1.46 \\
\hline Maranhão & -5.23 & 0.05 & -1.75 & -4.71 & -3.83 & -1.20 & -0.86 & -0.72 & -2.00 & -2.18 \\
\hline Paraíba & -1.00 & 1.45 & 0.30 & -1.02 & -1.44 & -3.24 & -0.20 & -0.56 & -2.02 & -1.55 \\
\hline Pernambuco & 0.27 & 1.32 & 0.90 & -1.20 & -0.45 & -1.72 & -0.97 & -0.89 & -0.14 & -2.57 \\
\hline Piauí & -4.57 & 0.28 & -0.86 & -4.53 & -4.39 & -3.23 & -0.97 & -0.87 & -0.14 & -1.26 \\
\hline Rio Grande do Norte & 0.47 & 1.43 & 0.87 & 0.46 & 0.51 & -1.51 & -0.86 & -0.66 & -1.03 & -1.91 \\
\hline Sergipe & -1.74 & 0.77 & 0.82 & -0.32 & 0.37 & -1.05 & -1.48 & -1.68 & -0.89 & -2.55 \\
\hline Distrito Federal & 6.66 & 4.74 & 5.06 & 6.21 & 5.99 & -1.18 & -0.67 & -0.52 & -1.14 & -1.85 \\
\hline Goiás & 0.89 & 2.08 & 2.09 & 2.52 & 2.09 & -1.61 & -0.72 & -1.18 & -2.05 & -2.05 \\
\hline Mato Grosso do Sul & 0.62 & 2.53 & 2.13 & 1.71 & 1.12 & -1.24 & -0.63 & -0.65 & -2.29 & -1.48 \\
\hline Mato Grosso & 0.16 & 0.86 & 0.23 & -1.08 & -0.89 & -1.99 & -1.23 & -1.95 & -0.62 & -1.16 \\
\hline Espírito Santo & -1.23 & 0.69 & 0.37 & -0.32 & 1.61 & -1.73 & -0.96 & -1.14 & -0.80 & -3.15 \\
\hline Minas Gerais & 0.26 & 0.84 & 0.94 & 0.13 & 0.62 & -1.35 & -0.38 & -1.12 & -0.62 & -1.97 \\
\hline Rio de Janeiro & 6.07 & 3.09 & 4.35 & 5.98 & 5.85 & -1.04 & -0.95 & -1.18 & -0.81 & -2.57 \\
\hline São Paulo & 5.49 & 0.17 & 1.78 & 4.15 & 6.71 & -0.91 & -1.20 & -1.36 & -0.98 & -2.34 \\
\hline Paraná & -1.17 & 0.76 & 0.56 & 0.23 & 2.81 & -1.88 & -0.59 & -1.08 & -1.18 & -3.31 \\
\hline Santa Catarina & -0.63 & -1.49 & -1.29 & -0.06 & 2.50 & -1.17 & -0.69 & -1.26 & -1.94 & -1.12 \\
\hline Rio Grande do Sul & 1.07 & 0.10 & -0.16 & -0.45 & 1.32 & -1.83 & -0.82 & -0.79 & -0.60 & -2.09 \\
\hline
\end{tabular}

** In 'from North to South' geographical order. To operate Homothetic Competitive Effect $\left(\mathrm{CE}^{\mathrm{h}}\right)$ assumptions have been made. There are states with zero sectoral employment as follows: for mining sector: Acre in 1981, 1986, 1996, 2001, and 2006; Alagoas in 1996, Roraima in 1981, and for Amapá in 1986 and 1996. For financial industry: Amapá in 1996. In all these cases we assumed population growth rate for employment growth rate over the subperiods to estimate sectoral employment in each of those years. The assumptions we made yielded results that are consistent with the overall pattern of employment data in Brazil. However, due to lack of population data for 1981 and 1986 from the sources in Brazil we estimated population data for these latter two years by interpolation based on the pattern of population time series.

Table 5 compares Spearman rank correlation coefficients for states' growth rates, the industry-mix growth rates, and the competitive growth rates across five-year periods. As in Cochrane and Poot (2008), the highest rank correlation coefficients are found for the industry-mix growth rates. This indicates that a change in regional industry mix is a relatively long-term process and there is therefore relative high temporal persistence in the state ranking based on this shift-share decomposition component. 
The ranking based on the competitive growth rate is clearly more volatile over time. In several cases, the rank correlation is statistically insignificant. The same is true with respect to regional growth rates. Clearly, the relative performance of the states over the 1991/96 period was very different from previous periods (1981/86 and 1986/91) but also subsequently (1996/01).

Table 5: Persistence in Regional Employment Change and its Components

\begin{tabular}{cccc}
\hline Compare Ranking & $\begin{array}{c}\text { Regional Growth } \\
\text { Rate }\end{array}$ & $\begin{array}{c}\text { Industry-Mix Growth } \\
\text { Rate }\end{array}$ & $\begin{array}{c}\text { Competitive Growth } \\
\text { Rate }\end{array}$ \\
\hline 81/86 with $86 / 91$ & $0.5788^{* * *}$ & $0.5788^{* * *}$ & $0.5940^{* * *}$ \\
81/86 with $91 / 96$ & 0.2509 & $0.8675^{* * *}$ & 0.2851 \\
81/86 with $96 / 01$ & $0.6368^{* * *}$ & $0.9267^{* * *}$ & $0.6197^{* * *}$ \\
81/86 with 01/06 & $0.5372^{* * *}$ & $0.8932^{* * *}$ & $0.6020^{* * *}$ \\
86/91 with $91 / 96$ & 0.2039 & $0.8187^{* * *}$ & 0.2070 \\
91/96 with $96 / 01$ & 0.0812 & $0.8968^{* * *}$ & 0.1453 \\
96/01 with $86 / 91$ & $0.6410^{* * *}$ & $0.6917^{* * *}$ & $0.6654^{* * *}$ \\
86/91 with $01 / 06$ & $0.4243^{* *}$ & $0.4316^{* *}$ & $0.4359^{* *}$ \\
91/96 with $01 / 06$ & $0.4908^{* * *}$ & $0.7454^{* * *}$ & $0.3748^{*}$ \\
96/01 with 01/06 & $0.3944^{* *}$ & $0.8639^{* * *}$ & $0.3962^{* *}$ \\
\hline
\end{tabular}

Note: The table reports Spearman's Rank Correlation Coefficients. Coefficients are significant at the *10\%; $* * 5 \%$; ***1\% levels.

\section{Alternative Formulations}

One of the criticisms of classic shift-share analysis is that the industry-mix effect interacts with competitive effect. In other words, it is difficult from the shift-share identity to isolate regional performance that truly depends on a region's strengths because a region can grow faster either as a result of an 'appropriate' mix of industries that are also going well elsewhere, or as a consequence of being specialised (i.e. a high LQ) in a buoyant industry which is not found elsewhere. This section reviews and applies some of the shift-share extensions that were done to isolate the interaction between the industry-mix and competitive effects in a region's growth (Loveridge and Selting, 1998, pp. 43-49; Cochrane and Poot, 2008).

The first extension considered is the calculation of Esteban-Marquillas homothetic employment, which is the employment that a region $r$ would have had in industry $i$ if the share of industry $i$ in regional employment was the same as the share of industry $i$ in national employment:

$$
E H_{i r}^{t-1}=\frac{E_{i 0}^{t-1} E_{0 r}^{t-1}}{E_{00}^{t-1}}
$$

Hence, homothetic employment would be the same as actual employment if, and only if, $L Q=1$. The decomposition of competitive effect using equation (8) is:

$$
C E_{i r}^{t} \equiv C E H_{i r}^{t}+A E_{i r}^{t} \equiv\left(g_{i r}^{t}-g_{i 0}^{t}\right) \times E H_{i r}^{t-1}+\left(g_{i r}^{t}-g_{i 0}^{t}\right) \times\left(E_{i r}^{t-1}-E H_{i r}^{t-1}\right)
$$


The $C E H_{i j}^{t}$ measures the comparative advantage of region's sector $i$ compared to the nation ( $g_{i r}^{t}>g_{i 0}^{t}$ ) and $A E$ is the Esteban-Marquillas' allocative effect which depends on the extent to which the region $r$ is specialised in the industry $i$ (i.e. homothetic employment differs from actual employment).

The Esteban-Marquillas' extension can also be applied to the industry-mix effect. This is referred to as Esteban-Marquillas' second decomposition,

$$
\begin{aligned}
E_{i r}^{t}-E_{i r}^{t-1} \equiv & \Delta E_{i r}^{t} \equiv N E E M 2_{i r}^{t}+I M E M 2_{i r}^{t}+C E H_{i r}^{t}+A E_{i r}^{t} \\
& N E E M 2_{i r}^{t}=g_{i 0}^{t} \times E H_{i r}^{t-1} \\
& I M E M 2_{i r}^{t}=g_{i 0}^{t} \times\left(E_{i r}^{t-1}-E H_{i r}^{t-1}\right)
\end{aligned}
$$

$C E H_{i r}^{t}$ and $A E_{\text {ir }}^{t}$ are defined as in (9); $N E E M 2_{i r}^{t}$ is the Esteban-Marquillas modified national growth effect on industry $i$ in the $r^{\text {th }}$ between times $(t-1)$ and $t, I M E M 2_{\text {ir }}^{t}$ is the EstebanMarquillas modified industry-mix effect on industry $i$ in the $r^{\text {th }}$ region between times $(t-1)$ and $t$.

Cochrane and Poot (2008, p. 67) cite Kheil (1992) to show that:

$$
\sum_{i} N E E M_{i r}^{t}=\sum_{i} N E_{i r}^{t} \text { and } \quad \sum_{i} I M E M 2_{i r}^{t}=\sum_{i} I M_{i r}^{t}
$$

We can see that $C E H_{i r}^{t}$ and $C E_{i r}^{t}$ are closely linked via the location quotient $L Q_{i r}^{t}$ as follows:

$$
C E H_{i r}^{t}=\frac{C E_{i r}^{t}}{L Q_{i r}^{t}}
$$

in which the location quotient $L Q_{i r}^{t}$ is again defined as the ratio of the share of industry $i$ in region $r$ over the share of industry $i$ in the nation (as reported for 1981 in Table 3). Other authors also used homothetic employment in their extensions. Based on equations (2) and (3), Bishop and Simpson (1972) created alternative expressions for national growth and industrymix effects:

$$
\begin{gathered}
\Delta E_{i r}^{t}=E_{i r}^{t}-E_{i r}^{t-1} \equiv N E B I S_{i r}^{t}+I M B I S_{i r}^{t}+C E_{i r}^{t} \\
N E B I S_{i r}^{t} \equiv g_{00}^{t} \times E_{i r}^{t-1}+\left(g_{i 0}^{t}-g_{00}^{t}\right) \times E H_{i r}^{t-1} \\
I M B I S_{i r}^{t}=\left(g_{i 0}^{t}-g_{00}^{t}\right) \times\left(E_{i r}^{t-1}-E H_{i r}^{t-1}\right)
\end{gathered}
$$

The new components of the three equations above are:

$N E B I S_{\text {ir }}^{t}=$ the Bishop-Simpson modified national growth effect on industry $i$ in the $r^{\text {th }}$ region between $(t-1)$ and $t$.

$I M B I S_{i r}^{t}=$ the Bishop-Simpson modified industry-mix effect on industry $i$ in the $r^{\text {th }}$ region between $(t-1)$ and $t$;

We tested the relationship between different measures introduced above by Pearson correlation coefficients for each period and each measure for the 27 States with nine industries, i.e. 243 observations per period. The results are given in Table 6. 
Table 6: Simple Correlations between shift-share components

1981-1986 for the 27 States of Brazil

\begin{tabular}{|c|c|c|c|c|c|c|c|c|}
\hline & $I M$ & $C E$ & CEH & $A E$ & NEBIS & IMBIS & NEEM2 & IMEM2 \\
\hline$I M$ & 1 & & & & & & & \\
\hline$C E$ & 0.510 & 1 & & & & & & \\
\hline CEH & 0.436 & $\underline{0.965}$ & 1 & & & & & \\
\hline$A E$ & -0.287 & $\underline{-0.806}$ & $\underline{-0.934}$ & 1 & & & & \\
\hline NEBIS & 0.583 & $\overline{0.990}$ & $\overline{0.943}$ & -0.770 & 1 & & & \\
\hline IMBIS & $\underline{0.998}$ & $\overline{0.455}$ & $\overline{0.381}$ & -0.237 & 0.532 & 1 & & \\
\hline NEEM2 & $\overline{\mathbf{0 . 5 8 7}}$ & $\underline{0.996}$ & $\underline{0.955}$ & -0.790 & $\underline{0.994}$ & 0.535 & 1 & \\
\hline IMEM2 & 0.519 & -0.471 & -0.512 & 0.508 & -0.386 & 0.571 & -0.388 & 1 \\
\hline \multicolumn{9}{|c|}{ 1986-1991 } \\
\hline & $I M$ & $C E$ & $\mathrm{CEH}$ & $A E$ & NEBIS & IMBIS & NEEM2 & IMEM2 \\
\hline$I M$ & 1 & & & & & & & \\
\hline$C E$ & 0.418 & 1 & & & & & & \\
\hline CEH & 0.566 & 0.660 & 1 & & & & & \\
\hline$A E$ & -0.549 & -0.525 & -0.986 & 1 & & & & \\
\hline NEBIS & 0.468 & $\underline{0.929}$ & 0.714 & -0.603 & 1 & & & \\
\hline IMBIS & 0.999 & $\overline{0.387}$ & 0.554 & -0.541 & 0.439 & 1 & & \\
\hline NEEM2 & $\overline{0.519}$ & $\underline{0.993}$ & $\mathbf{0 . 6 8 7}$ & -0.558 & 0.930 & 0.490 & 1 & \\
\hline IMEM2 & 0.762 & $-\overline{-0.270}$ & 0.131 & -0.208 & -0.168 & 0.783 & -0.158 & 1 \\
\hline \multicolumn{9}{|c|}{ 1991-1996 } \\
\hline & $I M$ & $C E$ & $\mathrm{CEH}$ & $A E$ & NEBIS & IMBIS & NEEM2 & IMEM2 \\
\hline$I M$ & 1 & & & & & & & \\
\hline$C E$ & -0.012 & 1 & & & & & & \\
\hline CEH & -0.378 & 0.682 & 1 & & & & & \\
\hline$A E$ & 0.381 & -0.676 & -1.000 & 1 & & & & \\
\hline NEBIS & 0.054 & $\underline{0.974}$ & 0.615 & -0.609 & 1 & & & \\
\hline IMBIS & $\underline{0.998}$ & -0.067 & -0.416 & 0.419 & 0.002 & 1 & & \\
\hline NEEM2 & $\overline{0.070}$ & 0.996 & 0.646 & -0.640 & 0.975 & 0.015 & 1 & \\
\hline IMEM2 & $\underline{0.857}$ & $\overline{-0.525}$ & -0.673 & 0.672 & -0.454 & 0.884 & -0.453 & 1 \\
\hline \multicolumn{9}{|c|}{ 1996-2001 } \\
\hline & $I M$ & $C E$ & $\mathrm{CEH}$ & $A E$ & NEBIS & IMBIS & NEEM2 & IMEM2 \\
\hline$I M$ & 1 & & & & & & & \\
\hline$C E$ & 0.231 & 1 & & & & & & \\
\hline$C E H$ & 0.330 & $\underline{0.833}$ & 1 & & & & & \\
\hline$A E$ & -0.322 & $\overline{-0.421}$ & -0.853 & 1 & & & & \\
\hline NEBIS & 0.613 & 0.816 & $\overline{0.687}$ & -0.356 & 1 & & & \\
\hline IMBIS & $\underline{0.999}$ & $\overline{0.219}$ & 0.321 & -0.320 & 0.605 & 1 & & \\
\hline NEEM2 & $\overline{0.467}$ & $\underline{0.968}$ & $\underline{0.845}$ & -0.471 & $\underline{0.899}$ & 0.455 & 1 & \\
\hline IMEM2 & 0.977 & $\overline{0.019}$ & 0.157 & -0.239 & 0.454 & $\underline{0.980}$ & 0.268 & 1 \\
\hline \multicolumn{9}{|c|}{ 2001-2006 } \\
\hline & $I M$ & $C E$ & $\mathrm{CEH}$ & $A E$ & NEBIS & IMBIS & NEEM2 & IMEM2 \\
\hline$I M$ & 1 & & & & & & & \\
\hline$C E$ & 0.365 & 1 & & & & & & \\
\hline CEH & 0.348 & $\underline{0.985}$ & 1 & & & & & \\
\hline$A E$ & -0.324 & -0.947 & $\underline{-0.989}$ & 1 & & & & \\
\hline NEBIS & 0.420 & 0.995 & 0.979 & -0.942 & 1 & & & \\
\hline IMBIS & 0.994 & $\overline{0.259}$ & $\overline{0.241}$ & $\overline{-0.221}$ & 0.316 & 1 & & \\
\hline NEEM2 & 0.437 & 0.997 & $\underline{0.980}$ & -0.942 & $\underline{0.996}$ & 0.334 & 1 & \\
\hline IMEM2 & 0.178 & $\underline{-0.851}$ & $\underline{-0.845}$ & $\overline{0.819}$ & $\overline{-0.814}$ & 0.288 & $\underline{-0.807}$ & 1 \\
\hline
\end{tabular}

Notes: Bold - Significant at $1 \%$ level (2 tailed); Italics - Significant at $5 \%$ level (2 tailed). Correlation coefficients of absolute value of 0.8 or above are underlined. 
$I M$ is highly correlated with IMBIS and IMEM2, except for the 2001-2006 period in which the correlation between IM and IMEM2 is low; $C E$ is highly correlated with $C E H$; NEBIS is highly correlated with NEEM2. IM and CE are uncorrelated in three of the subperiods. ${ }^{12}$ These results are qualitatively similar to those found by Cochrane and Poot (2008) for New Zealand. However, even more of the 28 correlation coefficients per period are statistically significant (positive or negative) in the Brazilian case than in the New Zealand case.

It is also useful to consider a comparison between the findings in this paper and those of Loveridge and Selting (1998, p. 52). However, Loveridge and Selting calculated the shiftshare component extensions for Minnesota from 1979 to 1988 by using income rather than employment. They also calculated correlations for the entire study period, rather than for divided small sub-periods. Therefore, Loveridge and Selting's (1998) results are verified here for each sub-period by considering only significant correlations in both studies. Identical results in both studies are: $A E$ and $C E H$ : the correlation is approximately $-1 ; I M B I S$ and $I M$ : positive correlation; NEEM2 and IM: positive correlation; IMEM2 and IM: 0.50 for both studies when considering the first sub-period, but other sub-periods still exhibit a statistically significant positive correction between these measures, except the last one; NEBIS and IM: positive correlation; NEBIS and CE: positive correlation, however, in the Brazilian case, the correlation is much higher; NEBIS and NEEM2: identical positive correlation of 0.9; IMBIS and NEEM2: positive, even though the correlation in Brazil is much higher; IMBIS and IMEM2: identical positive correlation of 0.8 .

In general, we can conclude that while the extensions are theoretically attractive, in practice the information contained in the alternative measures can often be proxied by the basic, and easily interpretable, measures. The cross-study comparison shows that this is the case for the Brazilian, US and New Zealand data. However, as we will show in the next two sections, extensions that introduce a spatial dimension add an important and informative component to shift-share analysis.

\section{Exploratory Spatial Analysis of Shift-Share Components}

This section examines the spatial distribution of the industry-mix and competitive effects of the traditional shift-share decomposition. The tools of spatial autocorrelation analysis that are used include Moran's I and cluster maps (Getis, 1991; Anselin, 1995; Cochrane and Poot, 2008; Le Gallo and Kamarianakis, 2010). ${ }^{13}$ Spatial autocorrelation is increasingly recognised as a major issue in econometric analysis, because the levels of many socio-economic variables are not random in space. In other words, those levels depend on the geographical location of any given region $r$. It often matters whether region $r$ has many neighbours or is

12 These two effects only have a correlation for the 1981-1986 period (0.510) and for 1986-1991 (0.418) that is significant at 1 percent and 5 percent levels, respectively.

13 Although there are a number of other spatial autocorrelation indicators such as Geary's ci, Getis and Ord's G1i, and Getis and Ord's G2i (see Pisati, 2010; Newton, 2001). 
relatively isolated (Anselin, 1989; Biles, 2003; Nazara and Hewings, 2004; Autant-Bernard, Mairesse and Massard, 2007). Researchers who ignore the problem of spatial autocorrelation are more likely to estimate misguided models.

One global (i.e. summary across space) measure of spatial autocorrelation is Moran’s I, which is defined as follows:

$$
I=\frac{\frac{1}{n} \sum_{i=1}^{n} \sum_{r=1}^{n} W_{i r}\left(z_{i}-\bar{z}\right)\left(z_{r}-\bar{z}\right)}{\sigma^{2}(z)}
$$

In this equation $z_{i}$ is a variable observed at location $i$ with $i=1, \ldots, n$ ( $n=27$ in the application to Brazilian states below), $W_{i j}$ is the spatial weights matrix that portrays interaction between all pairs of regions $i$ and $r(i ; r=1, \ldots, 27) ; \bar{z}$ is the sample average of $\mathrm{z}$ and $\sigma^{2}(z)$ is the sample variance of $z$. The spatial weights matrix can be created by means of software or manually. Moran's $I$ autocorrelation measure ranges from -1 to +1 . Positive values of Moran's $I$ indicate positive spatial correlation, negative values suggest that all regions are surrounded by regions that are 'opposites' (in practice this is rarely observed), and a zero Moran's $I$ the absence of spatial correlation. The interpretation of Moran's $I$ is based on the four quadrants in which the plot of the measure of the regions' interactions against the variable of interest belongs:

The four different quadrants of the scatterplot correspond to the four types of local spatial association between a region and its neighbours: $\mathrm{HH}$ denotes a region with a high value surrounded by regions with high values; LH a region with a low value surrounded by regions with high values, and so on. Quadrants HH and LL (respectively $\mathrm{LH}$ and $\mathrm{HL}$ ) refer to positive (respectively negative) spatial autocorrelation indicating spatial clustering of similar (respectively dissimilar) values. (Le Gallo and Kamarianakis, 2010, p. 6) ${ }^{14}$.

The simplest spatial interaction matrix is one in which interaction is determined by contiguity, with ' 1 ' in the original matrix indicating contiguity and ' 0 ' indicating noncontiguity. To create weights, the matrix is row-standardised (each row element is divided by the row sum).

A geographic evaluation of spatial autocorrelation is achieved by LISA (Local Indicators of Spatial Association) because these indicators allow the researcher to identify 'outlier regions'. This is illustrated by significance and cluster maps in which values of the variable of interest are geo-coded, and the levels are indicated by colour or shading on a map.

14 These quadrants are also known in the spatial econometrics literature as: High-High=hot spots; LowHigh=spatial outliers; High-Low=spatial outliers, Low-Low=cold spots, and locations with no significant spatial autocorrelation. 
A LISA is a statistic that satisfies two criteria (Cochrane and Poot, 2008, p. 71; Le Gallo and Kamarianakis, 2010, p. 6):

(i) The LISA for each observation gives an indication of significant spatial clustering of similar values around that observation;

(ii) The sum of the LISA for all observations is proportional to a global indicator of spatial association.

The local version of Moran's I statistic is a LISA and expressed as follows:

and hence

$$
\left.I_{i}=\left(z_{i}-\bar{z}\right) \sum_{j=1}^{n} W_{i j}\left(z_{j}-\bar{z}\right)\right]
$$

$$
I \equiv \frac{1}{n \sigma^{2}(z)} \sum_{i=1}^{n} I_{i}
$$

There are two important issues in the analysis of local Moran's $I_{i}$, as defined in equation (19) above:

Firstly, the local Moran's $I_{i}$ is not approximately normally distributed. This difficulty has been overcome in practice in a relatively straightforward manner by using a conditional randomisation or permutation approach to yield empirical pseudo significance levels.

A second complicating factor arises from the fact that the LISA statistics for individual locations will tend to be correlated which, along with the related problem of multiple comparisons, will lead to a flawed interpretation of the level of significance. Anselin suggests employing either the Bonferroni or Sidak correction to account for the multiple comparisons. However, the assumption of multivariate normality in the case of the Sidak correction is unlikely to be met by spatial data, while a Bonferroni correction may be too conservative. (Cochrane and Poot, 2008, p. 71).

In what follows, Moran's I scatterplots and cluster maps are presented for the IndustryMix (IM) and Competitive Effect (CE) components of the classic shift share analysis of section 4. The chosen values for IM and CE for each of the cluster maps are the averages across the five sub-periods. The spatial weights matrix for Moran's $I$ is a simple first order row-standardised 'queen's contiguity' matrix of Brazil that was created in Microsoft Excel. Queen's contiguity means that regions are considered contiguous if they have either a common border or a common edge. ${ }^{15}$.

15 On the other hand, rook contiguity and bishop contiguity consider regions as contiguous if and only if they share a common border and a common edge, respectively. These definitions can directly be downloaded from www.s4.brown.edu/s4/Training/Modul2/GeoDa2.pdf. 
Moran's I scatterplots for both IM and CE were estimated and the Moran's I significance levels were calculated by an OLS regression of the spatially weighted value for all regions outside any particular region against the value of the variable in that particular region. ${ }^{16}$ This OLS regression is precisely what is represented by equation (18). The Moran scatter plot for the IM effect is displayed in Figure 2. Moran's I (i.e. the slope of the regression line) is positive (0.4563) and statistically significant at the 1 percent level. This indicates that there is a clear pattern of a positive spatial association for the IM effect. This is also supported by the cluster map. (See Figure 3), which shows a clear pattern of a contiguous area with high levels in industry-mix (i.e., hot spots). This area involves the following states (middle-west-northwest space): Distrito Federal, Goiás, Mato Grosso, Rondônia, Acre, Amazonas, Roraima; and two pairs of an 'island' neighbouring states, which are (southeast) São Paulo-Rio de Janeiro and (northeast) Rio Grande do Norte-Paraiba, and an isolated 'island’ Amapá.

Figure 2: Moran’s I Scatterplot, Industry-Mix (pooled 5 sub-periods of 5 years)

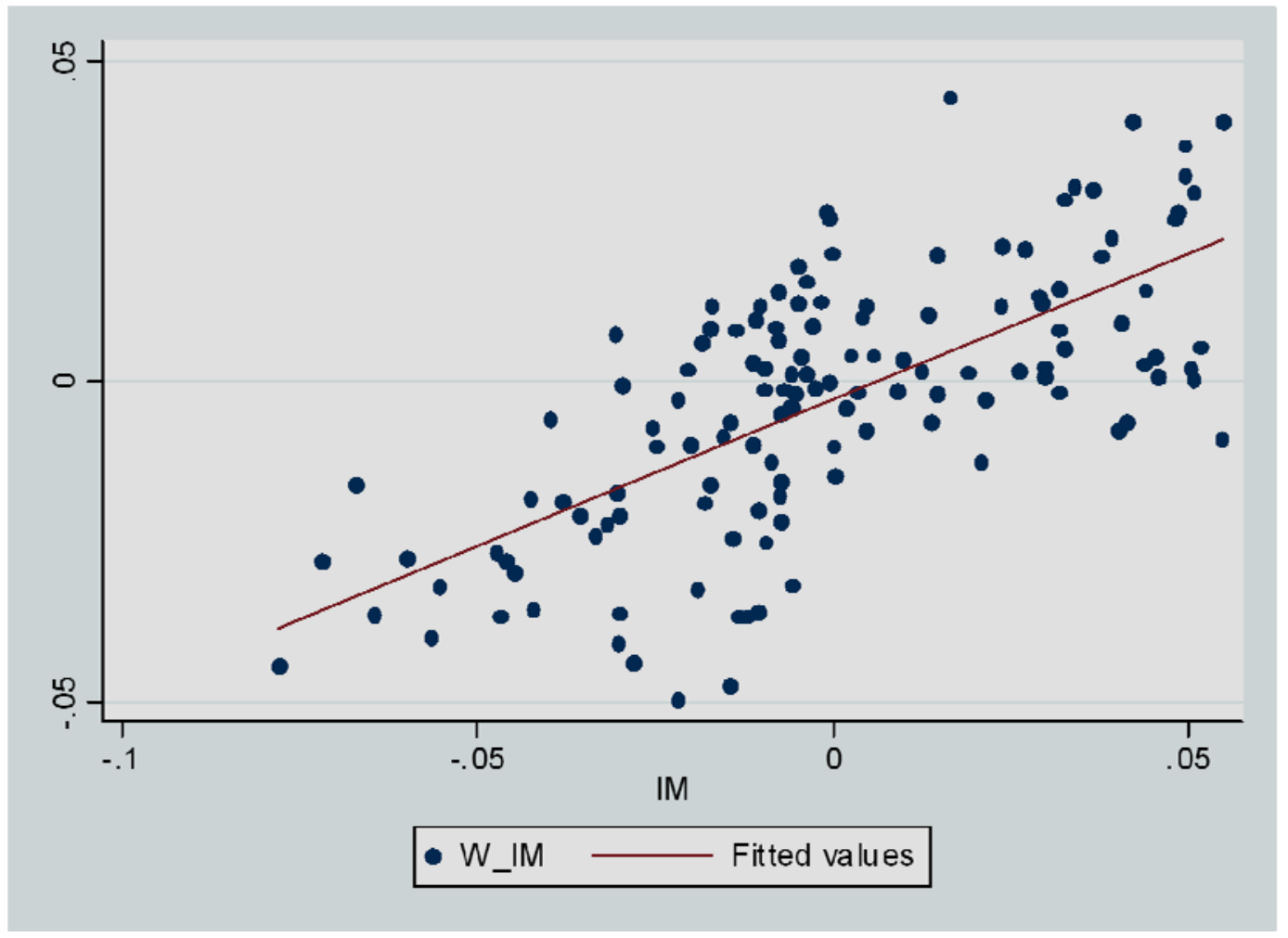

16 To address the problem of small sample size, we pooled the data to obtain 135 observations (or, 27 states times 5 sub-periods). 
Figure 3: Industry-Mix Cluster Map (average of 5 sub-periods of 5 years)

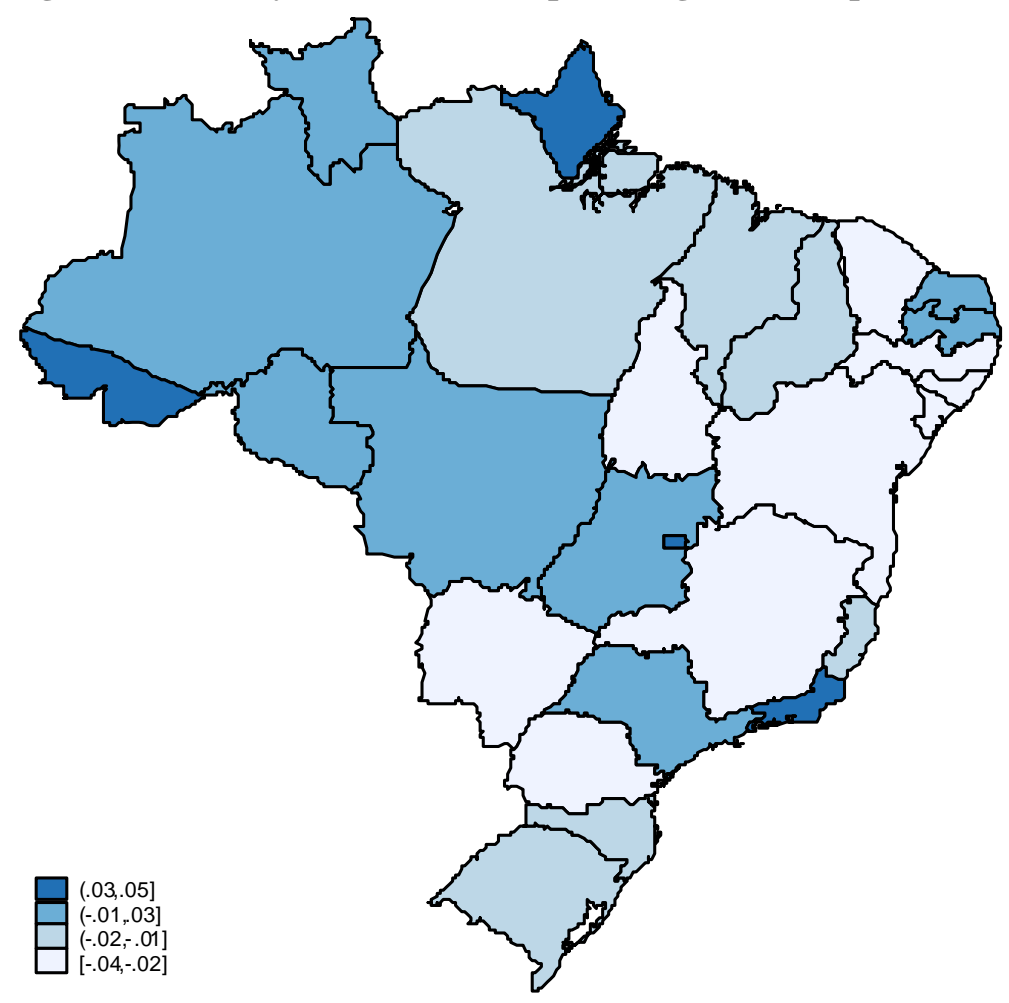

On the other hand, there is another cluster of contiguous states with low industry-mix levels (cold spots), which are (in south-east and north-northeast land areas): Minas Gerais, Bahia, Tocantins, Sergipe, Alagoas, Pernambuco and Ceará, and (in centre-west and south land area): Mato Grosso do Sul-Paraná.

For the CE effect, the Moran's I scatter plot (Figure 4) also shows a positive (0.3375) and statistically significant Moran's I. However, comparing Figures 2 and 4 it is clear that there is greater spatial correlation in the industry mix effect than in the competitive effect. A similar result was observed by Cochrane and Poot (2008). The cluster map Figure 5 shows hot spots located in (contiguous) northern states of Rondônia, Acre, Amazonas, and Roraima; northeast states of Pernambuco-Paraíba-Rio Grande do Norte; southeast-centre-west states of Espírito Santo, Minas Gerais and Mato Grosso do Sul, and in 'islands’ Amapá, Tocantins, and Distrito Federal. On the other hand, the cold spots are found along the east coast of Brazil, namely in the southeastern states of São Paulo and Rio de Janeiro and in the northeast-north land area (Piauí, Maranhão, and Pará), which overlaps an area with a relatively poor industry-mix, and ‘islands’ of Goiás and Rio Grande do Sul. 
Figure 4: Moran's I Scatterplot, Competitive-Effect (pooled 5 sub-periods of 5 years)

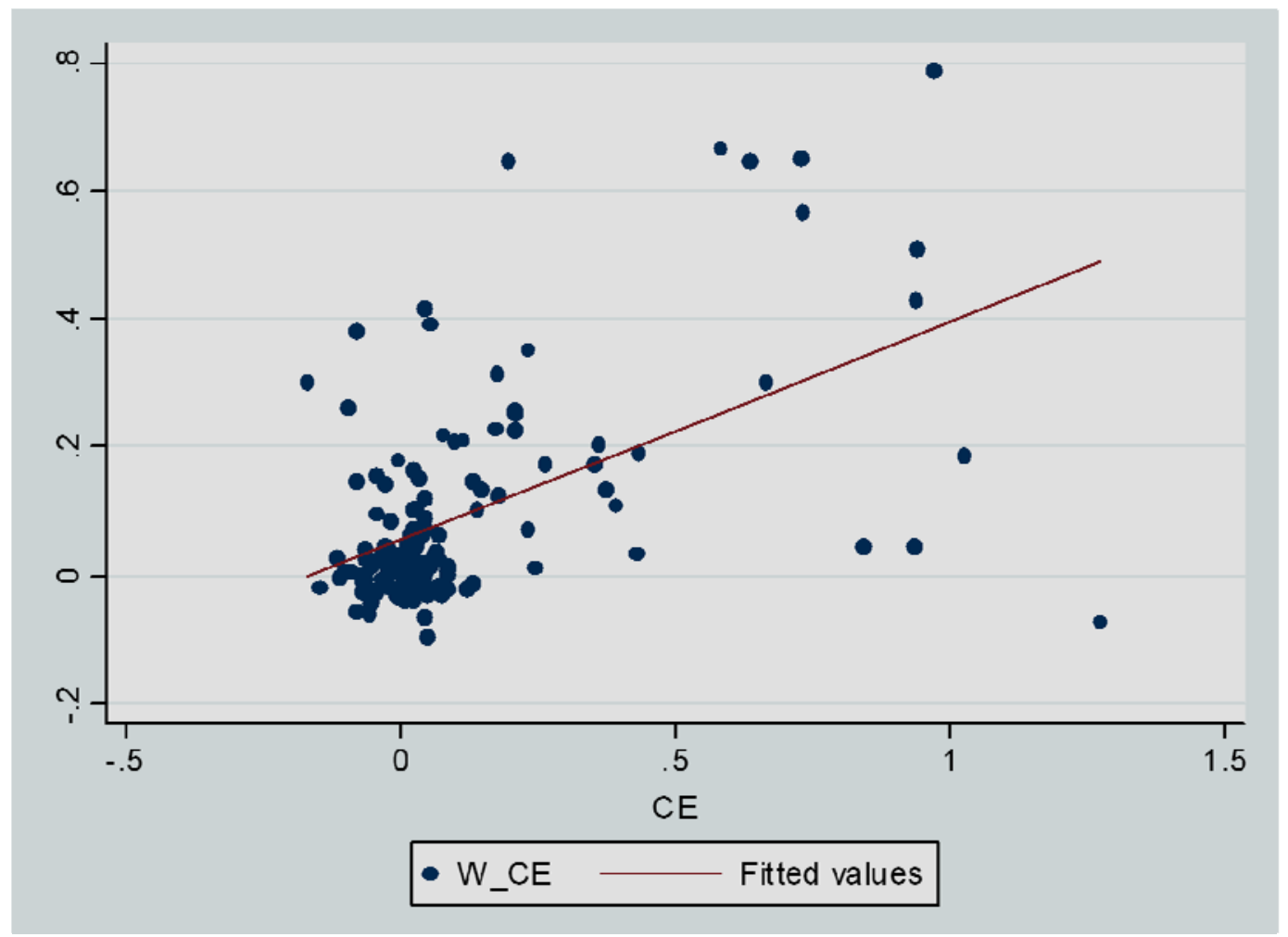

Figure 5: Competitive Effect Cluster Map (average of 5 sub-periods of 5 years)

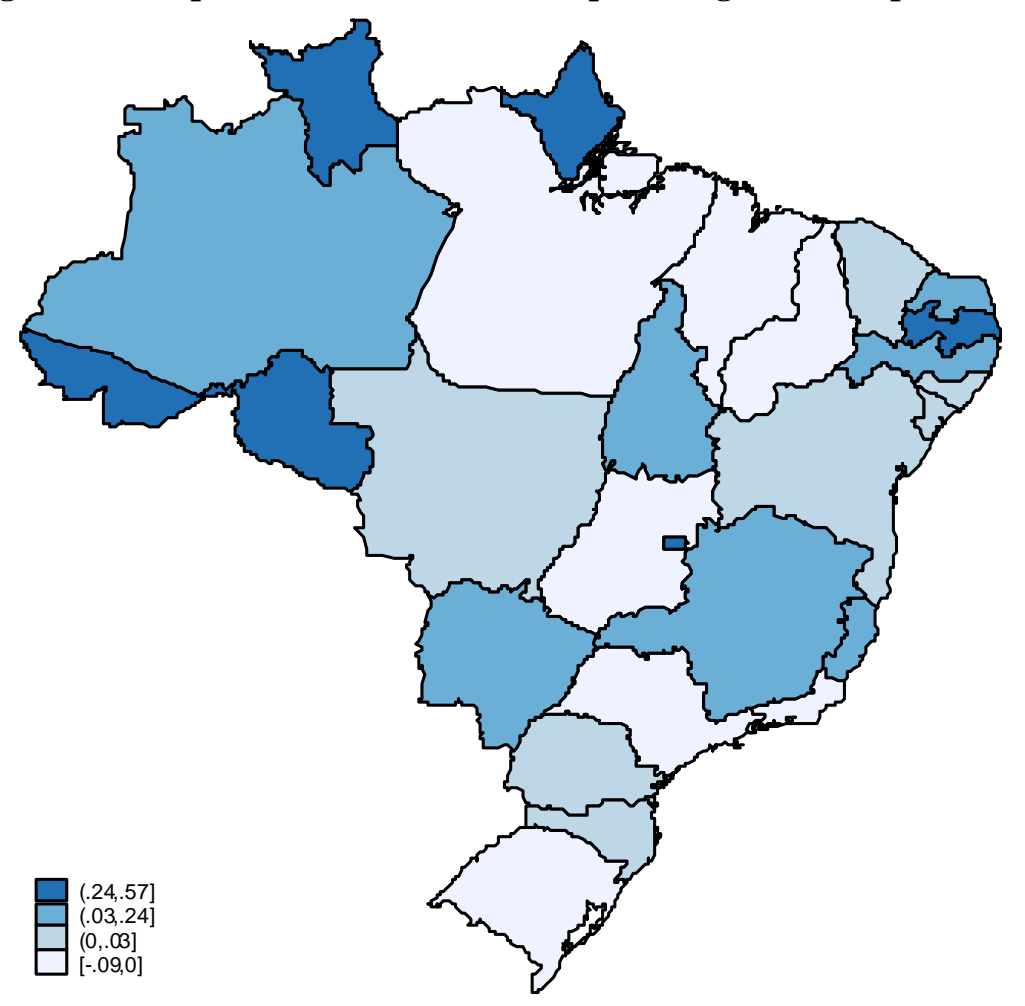


The economic interpretation of the results above is that two clusters of extremes (HighHigh versus Low-Low) ${ }^{17}$ can be observed, which is consistent with the positive spatial autocorrelation across states in Brazil generally and the argument that scale economies may arise as a consequence of local agglomeration of economic activities (Krugman, 1991). The evidence, based on the two shift-share components, in favour of economic agglomeration theory is as follows: the industry-mix result indicates low specialisation for many states. ${ }^{18}$ This finding reconfirms many previous studies for Brazil (Rolim, 2008; Daumal and Zignago, 2010, pp. 747-748, and footnote 22, p. 747) that found convergence across states. However, this convergence is due to the improvement of the industry-mix (i.e. greater diversity) for the less developed middle-west and northern states rather than specialisation. ${ }^{19}$

In fact, a long-run analysis reveals that, when considering annual data for sectoral employment of all states except Tocantins ${ }^{20}$, the average Hirschman-Herfindahl Index (HHI) is quite stable in Brazil. This index is defined as follows:

$$
\mathrm{HHI}_{\mathrm{i}}=\sum_{\mathrm{j}} \mathrm{s}_{\mathrm{ij}}^{2}
$$

Where: $\mathrm{s}_{\mathrm{ij}}$ is the employment share of the sector $j$ in state $i$ 's total employment.

Figure 6: Hirschman-Herfindahl Index, Brazil

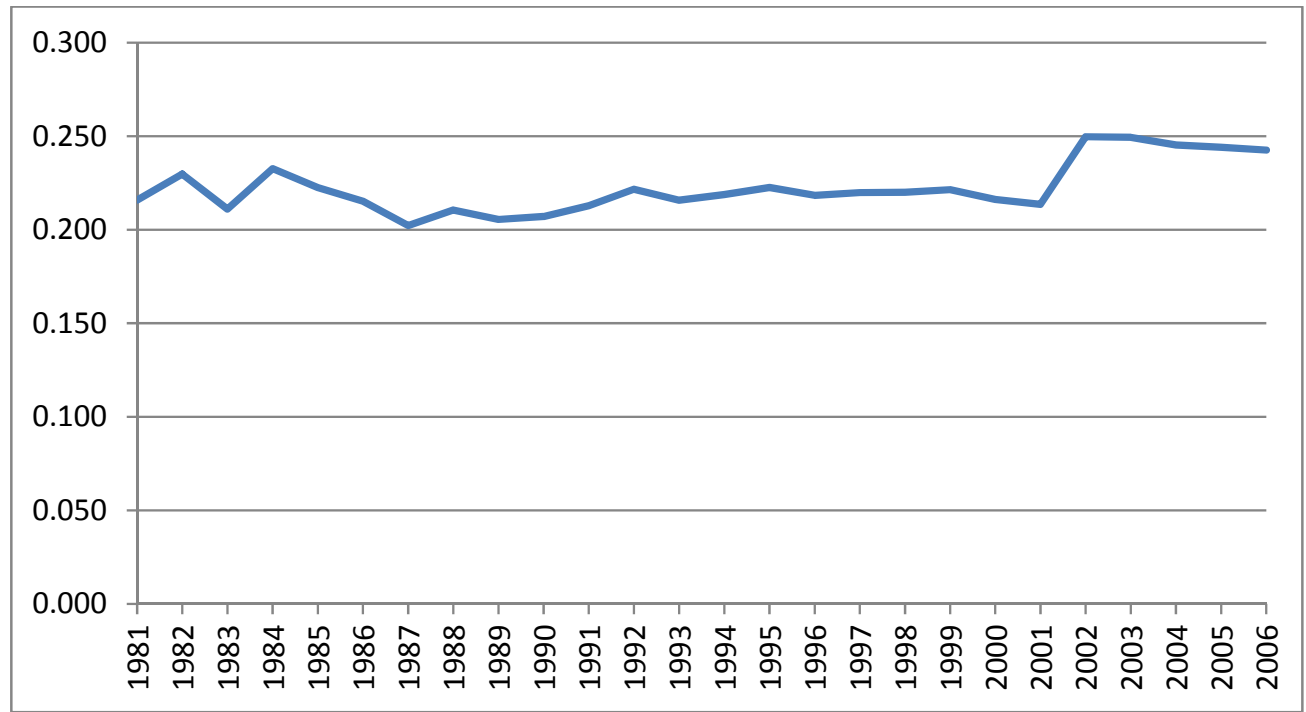

17 This result suggests interstate mobility among businesses may be low.

18 On the map for industry-mix average, these states are: Amapá, Roraima, Amazonas, Acre, Rondônia, Mato Grosso, Goiás, Distrito Federal, São Paulo, Rio de Janeiro, Rio Grande do Norte, and Paraiba. These states are essentially from north and middle-west which are the regions benefited from convergence from 1981 to 2006.

19 A conclusion based on cross-sectional data may be misguided. Although northern states were more specialised in the 1981 cross-section (see Table 3), the analysis of the long-run trend of the so-called Hirschman-Herfindahl Index (see the main text) indicates that those lagging states increased their competitiveness over time due to lesser specialisation relative to both the nation and the other states.

20 This state has been excluded due to a lack of state sectoral data from 1981 to 1991. 
Figure 6 shows that HHI oscillates between 0.20 and 0.23 from 1981 to 2001. From 2001, it increases to 0.25 in 2002, then falls to 0.24 in 2006. Nevertheless, the average of HHI for the period 1981-2006 varies considerably across states. Overall, the northern states, which had the highest growth rates, were less specialised (higher industry-mix effect) with the lowest averages of HHI (lesser than 0.20) and the northeastern states were more specialised (lower industry-mix effect) with the highest averages of HHI (higher than 0.22). Generally, a high average industry-mix indicates that the industrial structure of the fastest growth states has been diversified. On the other hand, the result from Figure 5 clearly shows a higher performance of the northern states which are some of the lagging ones, while the most developed south-eastern states of São Paulo and Rio de Janeiro had relatively lower competitiveness. The explanation for higher growth for the lagging regions is as follows. Due to their low income level and their early stage of development, small increases in capital, average education and infrastructure improvement have a large effect on their growth rates. This result supports the neoclassical beta convergence hypothesis (see also Resende, 2011 and the references therein).

\section{Spatial Shift-Share Analysis}

While section 7 investigated the spatial properties of the classic shift-share components, this section adds a new spatial component to the shift-share accounting framework in order to investigate regional growth of the 27 states in Brazil from 1981 to 2006. The regional growth rate is decomposed according to the taxonomy of spatial shift-share developed by Nazara and Hewings (2004). The growth rate for sector $i$ from time ( $t-1)$ to $t$ in region $r$ is linked to the interaction between regions as defined by spatial contiguity. The incorporation of a spatial effect on the growth rate of sector $i$ in region $r$ is done by means of a four step procedure. First, the spatial contiguity matrix (27x27) for the 27 states in Brazil that was used in the previous section is used again here. Spatial contiguity is indicated by ' 1 ' if states share a border or an edge, or zero otherwise ${ }^{21}$. Secondly, this spatial contiguity matrix is rowstandardised by taking the ratio between each cell and the sum of its matrix row. Thirdly, values of each cell of the row-standardised spatial weights matrix are multiplied by values of the corresponding sector employment in the states. Fourthly, the percentage changes of the spatially weighted sectoral employment from time $(t-1)$ to $t$ is defined as the spatial growth rate of the sector $i$ in the region $r$.

Nazara and Hewings (2004, p. 480) express these steps for both sector $i$ and region $r$ on the right-hand side of their equation (4) that we reproduce here [equation (22)]. This equation defines the spatially-weighted growth rate of a region's $r$ neighbours. To account for the neighbour effect in a region's $r$ growth rate, Nazara and Hewings replace the nation's sector $i$ growth rate, $G_{i}$, by region $r$ 's neighbour sector $i$ growth rate, which is labelled $g S_{i r}^{t}$ in equation (22) [Nazara and Hewings, 2004, p. 480, equation (5)]

${ }^{21}$ Hence queen contiguity is again adopted. The Distrito Federal is a region within Goiás state. They are assumed to share a border. 


$$
g S_{i r}^{t}=\frac{\sum_{k=1}^{R} \widetilde{w}_{r k} E_{i k}^{t}-\sum_{k=1}^{R} \widetilde{w}_{r k} E_{i k}^{t-1}}{\sum_{k=1}^{R} \widetilde{w}_{r k} E_{i k}^{t-1}}
$$

where: $g S_{i r}^{t}=$ Growth rate of employment in industry $i$ and region's $r$ neighbour between ( $t$ 1) and $t ; \widetilde{w}_{r k}$ is the element of row-standardised spatial weights matrix $\widetilde{W}$ that captures interactions between regions $r$ and $k ; E_{i k}^{t-1}$ and $E_{i k}^{t}$ are, respectively, employment in the $i^{\text {th }}$ industry in the $k^{\text {th }}$ region at time $(t-1)$ and $t$.

The decomposition of employment growth rate for sector $i$ from the period $t-1$ to $t$ in the region $r$ after the spatial effects have been incorporated in the classic shift-share method is as follows: substituting Nazara and Hewings (2004, pp. 480-481) equation (6) in their equation (5), the following four shift-share components are obtained: ${ }^{22}$

$$
\Delta E_{i r}^{t}=\left(E_{i r}^{t}-E_{i r}^{t-1}\right)=N E_{i r}^{t}+I M_{i r}^{t}+P S E_{i r}^{t}+S C E_{i r}^{t}
$$

The first two terms of the right-hand side of equation (23) are from the classic shiftshare method, as defined in section 2 (equations 2 and 3). The new terms that refer to spatial effects for growth of regions are:

$$
\begin{gathered}
P S E_{i r}^{t}=\left(g S_{i r}^{t}-g_{i 0}^{t}\right) E_{i r}^{t-1} \\
S C E_{i r}^{t}=\left(g_{i r}^{t}-g S_{i r}^{t}\right) E_{i r}^{t-1}
\end{gathered}
$$

The terms in the above equations are defined as: ${ }^{23}$

$P S E_{i r}^{t}=$ Potential Spatial Spillover Effect. It is the regional growth a region would have if spatial autocorrelation is 1, i.e. the corresponding regional growth rate is identical to the spatially weighted regional growth rates of surrounding regions. But surrounding regions could have the same industry-mix effect if there is spatial correlation in industry mix (which there is in the Brazilian case), so the potential spillover effect must be adjusted by subtracting the industry mix growth component, $g_{i 0}^{t}$. $P S E_{i r}^{t}$ is referred to as a potential spatial spillover effect because it is the maximum possible effect. The real spatial autocorrelation is likely to be much less than 1 so the actual spatial spillover will be far less than the potential spatial spillover.

$S C E_{\text {ir }}^{t}=$ Spatial Competitive Effect (or, the negative of neighbour-nation regional shift effect defined by Nazara and Hewings, 2004, p. 481).

22 From Nazara \& Hewings (2004, pp. 480-481) seven components can be identified. However, at the regional level, two components individually add to zero. These are: neighbour industry-mix effect and regional industry-mix effect (or, the negative own-region industry-mix effect). And there is a double counting for the other two: the neighbour-nation regional shift effect is equal to minus the neighbour-region regional shift effect. Thus, these components are excluded and we used a simplified version of the spatial shift-share identity with only four components.

23 The definition of $g_{i 0}^{t}$ is in section 2, and that of $g S_{i r}^{t}$ is in the above equation (22). 


\subsection{Spatial Shift-Share: Results for a Simple Contiguity Spatial Weights Matrix}

This sub-section presents the results of the spatial shift-share method. The average regional growth rates for the five sub-periods are compared with the average for each of the four components in all states. Figure 7 shows state growth rates and the national growth rate. ${ }^{24}$ There are three groups of states. The first group grew faster than the nation and had the highest average growth rates. This group includes: Roraima, Rondônia, Amapá, Acre, Distrito Federal, Pará, Amazonas, Tocantins, Mato Grosso, Rio Grande do Norte, Mato Grosso do Sul, and Espírito Santo. The second group had very similar growth rates to the nation. This group consists of Santa Catarina, Alagoas, Minas Gerais, Maranhão, Goiás, Ceará, Sergipe, and Piauí. Finally, the third group includes the remaining seven states which had a growth rate smaller than the national rate.

Figure 7: Growth rates versus national growth rate (average of 5 sub-periods of 5 years)

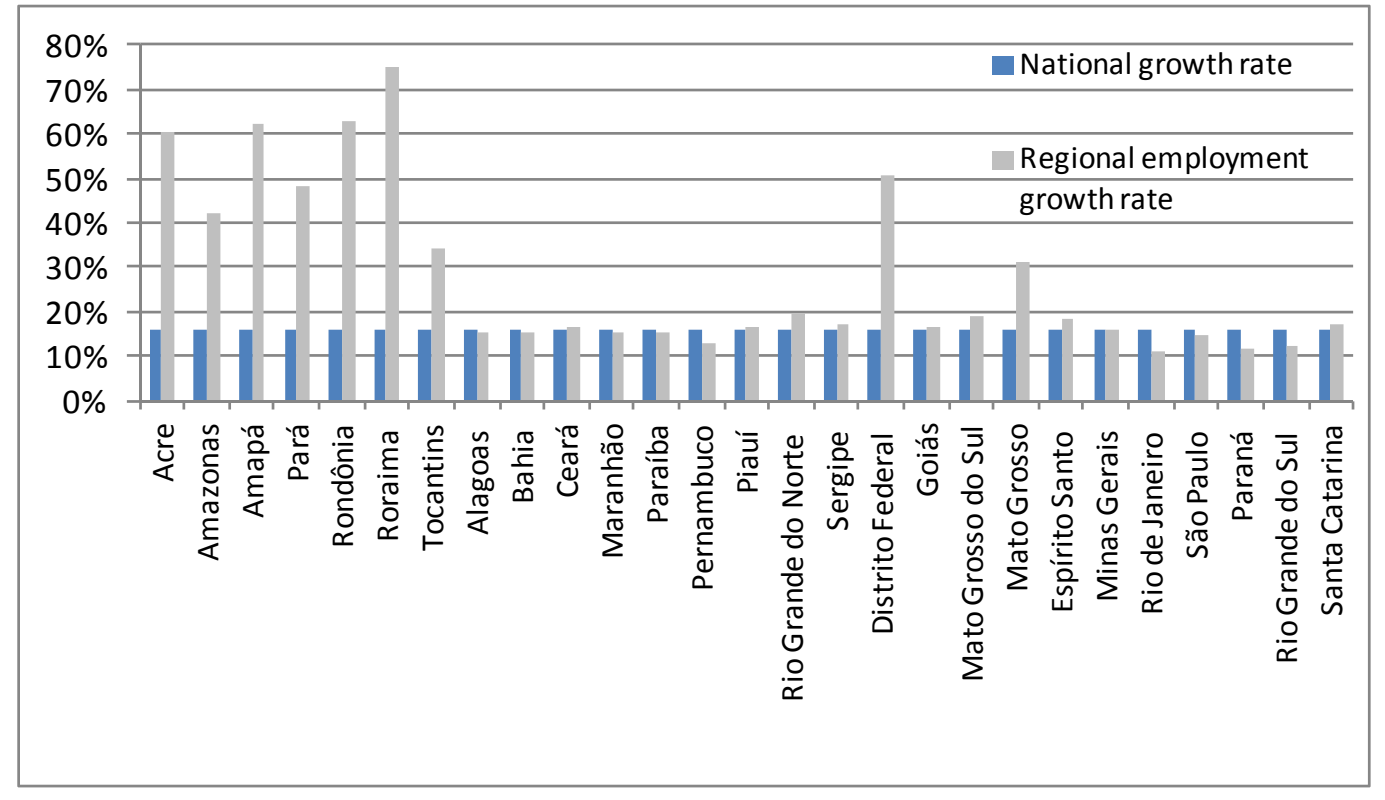

Figure 8 shows the regional growth rate and the industry-mix effect. The states with the highest growth rates also had a positive national industry-mix effect, i. e. those endowed with industries that were growing faster than average. These are seven states, namely Roraima, Rondônia, Amapá, Acre, Distrito Federal, Pará, and Amazonas. Rio de Janeiro and São Paulo are the only non-fast growing states that join this group with a positive national industry-mix effect. On the other hand, other states lacked important industries in terms of growth which yielded a zero (for Rio Grande do Norte, Goiás, and Mato Grosso do Sul), or a negative effect (for all the other 15 states) in this component. However, the industry mix effect is small relative to regional growth performance in all states.

24 In all figures that follow, the light shading refers to regional growth rate and the dark one to the defined components of the spatial shift-share. 
Figure 8: State growth rates versus national industry-mix effect

(Average of 5 sub-periods of 5 years)

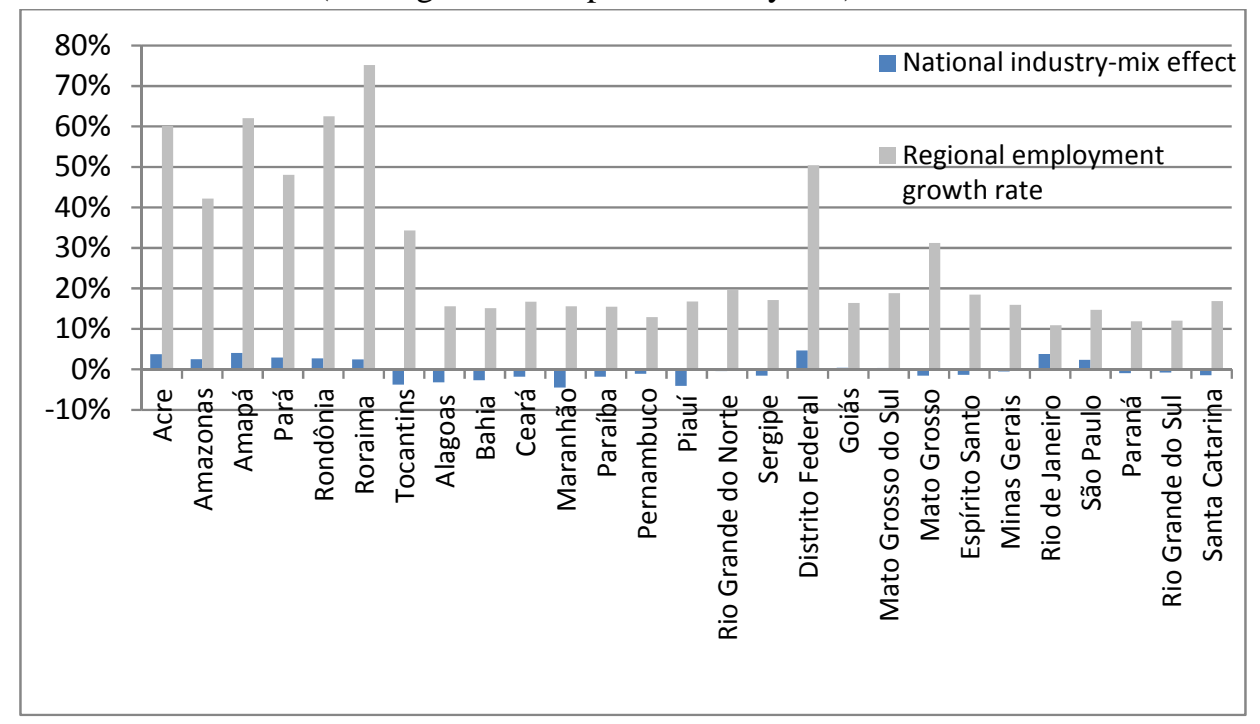

Figure 9 compares regional growth rates with the potential spatial spillover effect. Among the states that grew fastest are those that had the highest (positive) potential spatial spillover effect, i.e. their neighbouring states grew faster than the expected growth based on industry composition. ${ }^{25}$ These are (ordered according to the size of spatial spillover effect, at least 15 percent): Amapá, Acre, Roraima, Amazonas, Maranhão, Rondônia, and Mato Grosso. Some other states still had a positive potential spatial spillover effect (but only up to 7 percent) such as Tocantins, Pará, Piauí, Rio Grande do Sul, Bahia, Alagoas, Goiás, Paraiba, Ceará, Pernambuco, Rio Grande do Norte, and Sergipe. The remaining seven ${ }^{26}$ states had a negative potential spatial spillover effect ${ }^{27}$, indicating that they were surrounded by states with weak growth relative to the expected growth according to the industry composition.

Finally, Figure 10 shows the regional growth rate and the spatial competitive effect. Most of the states that grew fastest also had the highest (positive) spatial competitive effect, i. e. they grew faster than the surrounding regions. These are (ordered according to the size of spatial competitive effect, at least 13 percent): Distrito Federal, Roraima, Rondônia, Pará, Tocantins, Amapá, and Acre. Some other states still had a positive spatial competitive effect (but only up to 5 percent), such as Santa Catarina, Espírito Santo, Mato Grosso do Sul, Rio Grande do Norte, Mato Grosso, Ceará, Sergipe, Alagoas, Piauí, São Paulo, and Minas Gerais. For the remaining nine states, the spatial competitive effect was zero for Paraíba and negative for the other eight states ${ }^{28}$ due to smaller growth rates relative to growth rates of their neighbouring states, which indicates that their poor performance is particularly due to their own weaknesses.

25 Excluding Maranhão.

26 Excluding Paraná for which this effect was equal to zero.

27 It is worth noting that both São Paulo and Rio de Janeiro had the lowest level of this effect, -5 percent.

28 It is worth noting that for one fast grower, the northern state of Amazonas, this effect is also negative. Maranhão, Rio Grande do Sul and Rio de Janeiro had the lowest levels for this component, $-16,-5$, and -4 percent, respectively. 
Figure 9: State growth rates versus potential spatial spillover effect (Average of 5 sub-periods of 5 years)

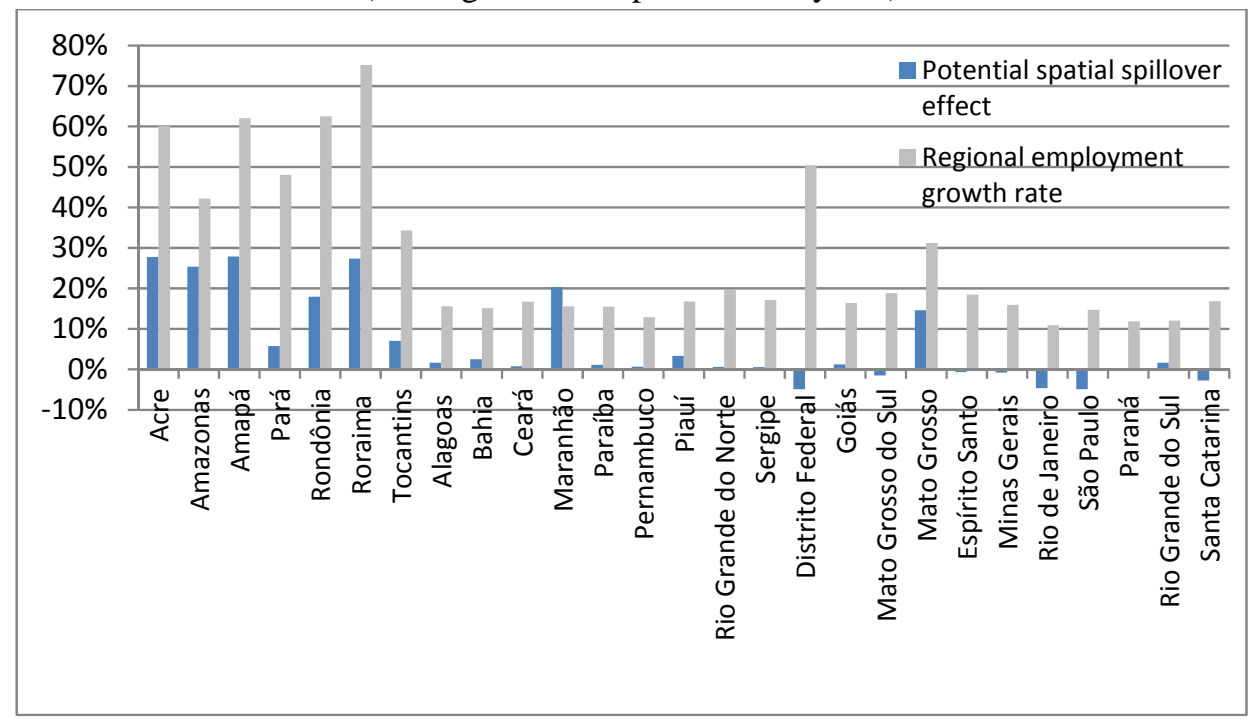

Figure 10: Growth rates versus spatial competitive effect

(Average of 5 sub-periods of 5 years)

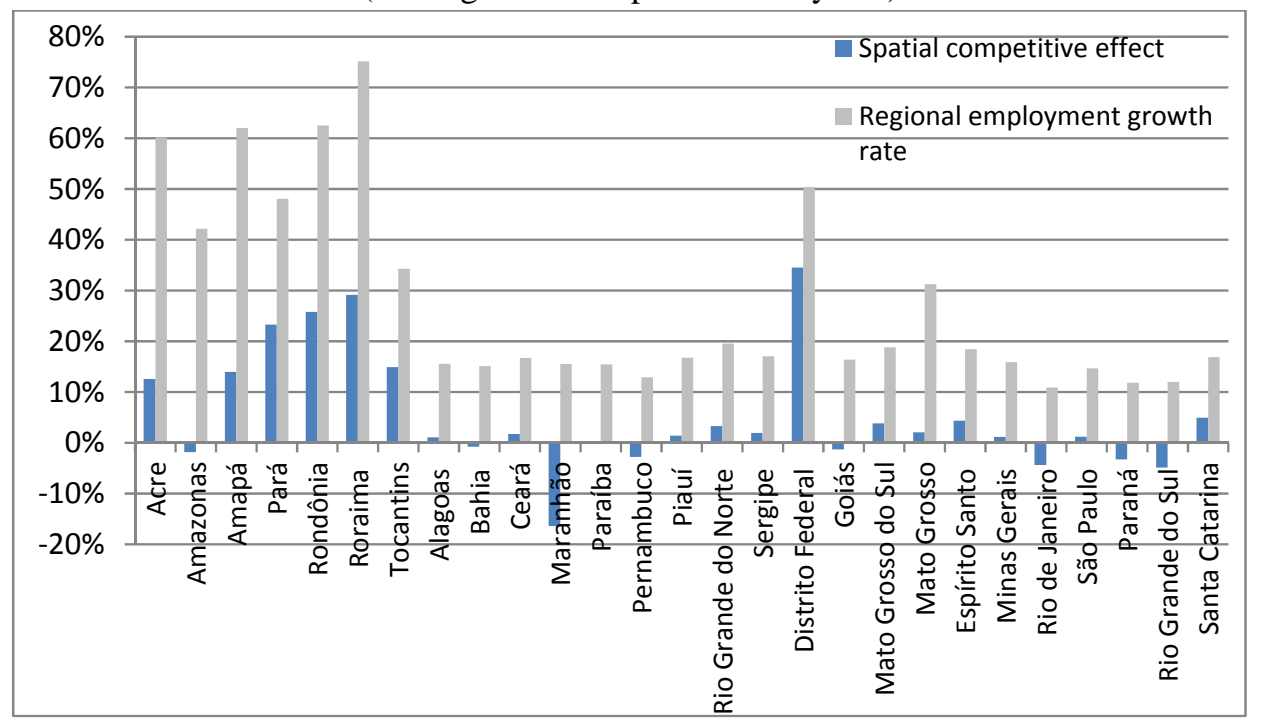

Inspection of the sub-periods indicated that the sub-period 1991-96 was atypical. Only four states grew fastest, namely Tocantins, Amapá, Roraima, and Maranhão, and among the other states, most had a moderate growth rate, between 8 and 16 percent. The characteristics for this period are that it had the lowest national growth rate and very low levels for the other three components, national industry-mix effect, potential spatial spillover effect, and spatial competitive effect for almost all states. On the other hand, the sub-period 1996-2001 stands out as the one with very negative spatial competitive effect for nine states, mostly located in the north and northeast regions. 


\subsection{Spatial Shift Share: Results for an alternative Spatial Weights Matrix}

A valid question in spatial shift-share analysis is whether the results are sensitive to the definition of the spatial weights matrix. In order to investigate this issue, an alternative spatial weights matrix is considered in this sub-section. This alternative row-standardised spatial weights matrix takes into account population data and distance data for the beginning year of each of the five sub-periods. Population data used refer to the 27 urban areas that constitute Brazilian state capitals. These urban areas were defined through observation of contiguous municipalities taken together in 2008 (see Matlaba 2012, Appendix 4.1). We calculated the urban areas population data by interpolation for the years in which there are no data from the official sources, that is, for the first three beginning years of the five sub-periods. ${ }^{29}$ For the other two beginning years, 1996 and 2001, the correlation between the original and calculated data is 0.99 , which shows the resemblance between both types of data. For consistency with the other previous three years, we used the calculated data in this study.

The Municipality Population Data used for construction of the urban areas were obtained from the Institute of Applied Economic Research (IPEA) and the Brazilian Institute of Geography and Statistics (IBGE). ${ }^{30}$ We obtained the matrix of distances between the 27 Brazilian state capitals from Brazil's Ministry of Transportation. The spatial weights matrix used to measure the states' interactions is based on the gravity model, which relates distance between regions and population size of those regions (see Getis, 1991, pp. 29-30; Bavaud, 1998, pp. 157-158; McCann, 2001, p. 202; Brakman, Garretsen and van Marrewijk, 2001, pp. 265-270), and is defined as: ${ }^{31}$

$$
\begin{aligned}
& w_{r k}^{*(t-1)}=D_{r k} / \sqrt{P_{r}^{t-1} P_{k}^{t-1}} \\
& w_{r k}^{t-1}=w_{r k}^{*(t-1)} /\left(\text { sum of } w_{r k}^{*(t-1)} \text { over } k\right)
\end{aligned}
$$

Where $D_{r k}$ is distance between regions $r$ and $k$; $P_{r}^{t-1}$ and $P_{k}^{t-1}$ is population sizes of the capitals $r$ and $k$ at time $(t-1)$, which is the initial year of sub-period under consideration.

Comparing the obtained results using this alternative spatial weights matrix with those above that used the queen contiguity matrix of spatial weights, it turns out that the results are very similar for all components in all states for each of the five-year sub-periods from 1981 to 2006 as well as for the averages for whole period. ${ }^{32}$ Therefore, in the Brazilian context, the first-order spatial weights queen contiguity matrix and the spatial matrix based on the gravity model can substitute for each other because both yield the same results.

29 These years are 1981, 1986, and 1991.

30 The IPEA data source has been briefly introduced in section 3. IBGE is one of the most important public socio-economic data sources and is the institution that conducts censuses in Brazil.

31 In fact, the gravity equation suggests that the spatial interaction between regions is inversely related to distance between pairs of regions and positively related with the product of economic size of the two respective regions. Here we used population as an indicator of the scale of regional economy.

32 Graphs are not shown here but are available upon request. 


\section{Conclusions}

This paper applied different techniques to analyse employment growth across 27 states in Brazil from 1981 to 2006. Three key conclusions can be drawn from the analysis. First, from the classic shift-share method we conclude that higher employment growth rates of the less developed regions are due to these regions' comparative advantage associated with high performance of the industry-mix and competitive effect components irrespective of the national structural change. This evidence confirms previous studies that found regional convergence in Brazil (Rolim, 2008; Daumal and Zignago, 2010). The reason for this convergence appears to be an improvement of diversity of the economies of the less developed regions (i.e. northern states) given that they had the smallest HirschmanHerfindahl Indexes as well as higher performance in the industry-mix component, rather than specialisation as previous studies have pointed out. Secondly, examination of the industrymix and competitive effect components employing exploratory spatial data analysis (ESDA) provided evidence of a positive spatial association for both components. This result supports agglomeration economies and beta convergence theories, as previously found (Resende, 2011, and the references therein), because, compared with the 1960s, nowadays economic activities are slightly less concentrated in the southern and more developed regions of Brazil.

Thirdly, the paper provided a simplified version of Nazara and Hewings's (2004) spatial shift-share taxonomy from which the role of spatial autocorrelation in regional growth in Brazil could be quantified in a straightforward way. Growth differentials in favour of northern and middle-west states are basically associated with their strengths in two regional components of the spatial shift-share, namely potential spatial spillover effect and spatial competitive effect that, together, outweigh the poor performance on national industry-mix effect for those lagging states. On the other hand, most states in Brazil had lower growth rates that were associated with their low rates of both spatial components. These results confirm the core-periphery framework which is associated with the importance of agglomeration forces in Brazil (Brakman, Garretsen and van Marrewijk, 2001). This association implies that, due to the large regional disparities and large scale of concentration in favour to the southeast-south regions (the core), a fast growth for the lagging regions (the periphery) is still less relevant to change the spatial pattern of economic activities, because the initial conditions that strongly favoured the core seem to have essentially permanent effects in Brazil. As a consequence, for instance, the observed modest growth rate for São Paulo (the core) still counts, given the scale of this state's economy, for much of the concentration of economic activities, population and income in Brazil.

A caveat of the available data is the high level of aggregation, i.e. the state level. Had employment data been available at the municipality level, rather than at the state level, this would have allowed a spatial regression approach to quantify the various components of regional growth. Given improving data availability in recent years, this could be an avenue for future research. 
Table 2: Classic Shift-Share Decomposition of Total Employment Growth Rate in Brazil’s States

\begin{tabular}{|c|c|c|c|c|c|c|c|c|c|c|c|c|c|c|c|c|c|c|c|c|c|c|c|c|}
\hline \multirow[b]{2}{*}{ State* } & \multicolumn{4}{|c|}{$1981-86$} & \multicolumn{4}{|c|}{$1986-91$} & \multicolumn{4}{|c|}{$1991-96$} & \multicolumn{4}{|c|}{$1996-2001$} & \multicolumn{4}{|c|}{ 2001-06 } & \multicolumn{4}{|c|}{ Five-Period Averages } \\
\hline & $g_{0 r}^{86}$ & $g_{00}^{86}$ & $m_{0 r}^{86}$ & $c_{0 r}^{86}$ & $g_{0 r}^{91}$ & $g_{00}^{91}$ & $m_{0 r}^{91}$ & $c_{0 r}^{91}$ & $g_{0 r}^{96}$ & $g_{00}^{96}$ & $m_{0 r}^{96}$ & $c_{0 r}^{96}$ & $g_{0 r}^{01}$ & $g_{00}^{01}$ & $m_{0 r}^{01}$ & $c_{0 r}^{01}$ & $g_{0 r}^{06}$ & $g_{00}^{06}$ & $m_{0 r}^{06}$ & $c_{0 r}^{06}$ & $g_{0 r}$ & $g_{00}$ & $m_{0 r}$ & $c_{0 r}$ \\
\hline Roraima & 121.8 & 17.7 & 1.7 & 102.4 & 62.7 & 16.2 & 3.2 & 43.4 & 54.9 & 9.1 & 2.7 & 43.1 & 37.0 & 11.1 & 5.0 & 20.9 & 99.4 & 26.5 & 0.0 & 72.9 & 75.1 & 16.1 & 2.5 & 56.5 \\
\hline ondônia & 4. & 7.7 & 3.3 & 93.8 & 41 & 16.2 & 2.9 & & & 9.1 & 2.4 & -3.3 & 28.2 & 11.1 & 3.9 & 13.2 & 121.4 & 26.5 & 1.0 & 94.0 & 02.5 & & 2.7 & 43.7 \\
\hline Amapá & 3.2 & 17.7 & 4.2 & 26.2 & 56.7 & 16.2 & 5.1 & 35.5 & 98.2 & 9.1 & 4.9 & 84.2 & 20.0 & 11.1 & 3.7 & 5.2 & 87.1 & 26.5 & 2.4 & 58.2 & 62.0 & 16.1 & 4.0 & 41.9 \\
\hline Acre & 96.3 & 17.7 & 5.5 & 73.1 & 30.5 & 16.2 & 4.4 & 10.0 & 16.4 & 9.1 & 3.8 & 3.6 & 34.0 & 11.1 & 5.0 & 18.0 & 123.5 & 26.5 & 0.0 & 97.1 & 60.2 & 16.1 & 3.7 & 40.3 \\
\hline Distrito Federal & 150.6 & 17.7 & 5.5 & 127.4 & 24.5 & 16.2 & 4.1 & 4.3 & 8.3 & 9.1 & 4.5 & -5.3 & 24.8 & 11.1 & 5.1 & 8.6 & 43.8 & 26.5 & 4.1 & 13.1 & 50.4 & 16.1 & 4.7 & 29.6 \\
\hline Pará & 39.3 & 17.7 & 4.0 & 17.5 & 36.3 & 16.2 & 2.9 & 17.2 & 16.2 & 9.1 & 2.6 & 4.5 & 53.3 & 11.1 & 3.0 & 39.2 & 95.2 & 26.5 & 2.1 & 66.7 & 48.1 & 16.1 & 2.9 & 29.0 \\
\hline nas & .1 & 17.7 & 4.8 & 19.6 & 36.7 & 16.2 & -0.1 & 20.6 & .0 & 9.1 & 1.5 & 2.4 & 26.1 & 11.1 & 3.4 & 1.5 & 3.0 & 26.5 & 3.0 & 3.5 & 42.2 & 16.1 & 2.5 & 23.5 \\
\hline Toca & .7 & 17.7 & -7.2 & 2.1 & 12.0 & 16.2 & 0.3 & -4.4 & 8.6 & 9.1 & -4.0 & 93.4 & 22.0 & 11.1 & -3.2 & 4.1 & 26.2 & 26.5 & -4.7 & 4.4 & 34.3 & 16.1 & -3.8 & 21.9 \\
\hline Mato Grosso & 52.0 & 17.7 & -1.8 & 36.1 & 53.0 & 16.2 & -0.4 & 37.2 & 10.7 & 9.1 & -1.7 & 3.3 & 24.1 & 11.1 & -1.7 & 14.7 & 16.4 & 26.5 & -2.0 & -8.0 & 31.2 & 16.1 & -1.5 & 16.7 \\
\hline Rio Grande & 23.7 & 17.7 & -1.0 & 7.0 & 25.2 & 16.2 & 0.6 & 8.5 & 11.8 & 9.1 & 0.2 & 2.5 & 10.4 & 11.1 & -0.6 & -0.1 & 26.7 & 26.5 & -1.4 & 1.6 & 19.6 & 16.1 & -0.4 & 3.9 \\
\hline ato & .1 & 7.7 & -0.6 & 7.0 & 0.7 & 16.2 & 1.9 & & 1.9 & 9.1 & 1.5 & 1.4 & 8.8 & 11.1 & -0.6 & -1.7 & 28.4 & 26.5 & -0.4 & 2.3 & 18.8 & 16.1 & 0.4 & 2.3 \\
\hline Espírito & .6 & 17.7 & -3.0 & 1.8 & 24.3 & 16.2 & -0.3 & 8. & 9.2 & 9.1 & -0.8 & 0.8 & 15.0 & 11.1 & -1.1 & 5.0 & 27.3 & 26.5 & -1.5 & 2.3 & 18.5 & 16.1 & -1.3 & 3.7 \\
\hline Sergipe & 12.2 & 17.7 & -2.8 & -2.8 & 16.4 & 16.2 & -0.7 & 1. & 13.2 & 9.1 & -0.9 & 5.0 & 7.2 & 11.1 & -1.2 & -2.7 & 36.4 & 26.5 & -2.2 & 12.1 & 17.1 & & -1.5 & 2.5 \\
\hline San & 20.1 & 17.7 & -1.8 & 4.2 & 16.4 & 16.2 & -2.2 & 2. & 7.8 & 9 & -2.5 & 1.2 & 17.8 & 11.1 & -2.0 & 8. & 22.2 & 26.5 & 1.4 & -5.6 & 16.9 & & -1.4 & 2.2 \\
\hline Piauí & 8.8 & 17.7 & -7.8 & -1.1 & 24.1 & 16.2 & -0.7 & 8.6 & 15.1 & 9.1 & -1.7 & 7.7 & 7.4 & 11.1 & -4.7 & 1.0 & 28.4 & 26.5 & -5.7 & 7.5 & 16.8 & 16.1 & -4.1 & 4.8 \\
\hline Ceará & 20.6 & 17.7 & -3.0 & 5.9 & 16.7 & 16.2 & -0.5 & 1. & 12.3 & 9.1 & -0.6 & 3.7 & 12.7 & 11.1 & -3.3 & 5.0 & 21.3 & 26.5 & -1.9 & -3.3 & 16.7 & 16.1 & -1.9 & 2.5 \\
\hline Goiás & & 17.7 & -0.7 & -16.9 & 40.7 & 16.2 & 1.4 & 23.2 & 2.1 & 9.1 & 0.9 & -7.9 & 15.4 & 11.1 & 0.5 & 3.8 & 23.8 & 26.5 & 0.0 & -2.8 & 16.4 & & 0.4 & -0.1 \\
\hline Minas Gerais & 19.0 & 17.7 & -1.1 & 2.4 & 17.4 & 16.2 & 0.5 & 0.8 & 8.2 & 9.1 & -0.2 & -0.7 & 9.8 & 11.1 & -0.5 & -0.8 & 25.2 & 26.5 & -1.3 & 0.1 & 15.9 & 16.1 & -0.5 & 0.3 \\
\hline & & .7 & -4.6 & & & .2 & & & & 9.1 & & & 2.1 & 1 & -3.6 & & 6 & 26.5 & -5.5 & 1.4 & 5.6 & & -3.2 & 2.7 \\
\hline Maranhão & 13.2 & 17.7 & -6.4 & 1.9 & 19.8 & 16.2 & -0.8 & 4.5 & 29.8 & 9.1 & -2.5 & 23.2 & 3.9 & 11.1 & -6.7 & -0.5 & 10.9 & 26.5 & -6.0 & -9.5 & 15.5 & 16.1 & -4.5 & 3.9 \\
\hline & & & -4.2 & & & .2 & & & & & & & & 1 & -3.0 & -11 & & 26.5 & -3.0 & & & & & 1.2 \\
\hline Bahia & 20.5 & 17.7 & -4.2 & 6.9 & 18.8 & 16.2 & -0.1 & 2. & 3.5 & 9.1 & -1.1 & -4.4 & 10.8 & 11.1 & -3.8 & 3.4 & 22.1 & 26.5 & -4.5 & 0.1 & 15.1 & 16.1 & -2.7 & 1.7 \\
\hline São Pa & 20.0 & 17.7 & 4.6 & -2.3 & 8.2 & 16.2 & -1.0 & -7.0 & 10.0 & 9.1 & 0.4 & 0.4 & 9.2 & 11.1 & 3.2 & -5.1 & 26.0 & 26.5 & 4.4 & -4.8 & 14.7 & 16.1 & 2.3 & -3.7 \\
\hline Pernambuco & 14.4 & 17.7 & -1.4 & -1.9 & 16.6 & 16.2 & 0.4 & 0.1 & 3.0 & 9.1 & 0.0 & -6.1 & 12.5 & 11.1 & -1.3 & 2.7 & 18.0 & 26.5 & -3.0 & -5.5 & 12.9 & 16.1 & -1.1 & -2.1 \\
\hline Rio & 10.1 & 17. & -0.8 & & & 10.2 & -0.7 & & & & -0.9 & -2.0 & & & -1.0 & 1.1 & & 26.5 & -0.8 & & & & -0.8 & -3.2 \\
\hline Paraná & 8.0 & 17.7 & -3.1 & -6.7 & 12.9 & 16.2 & 0.2 & -3.4 & 8.9 & 9.1 & -0.5 & 0.3 & 7.7 & 11.1 & -0.9 & -2.5 & 21.8 & 26.5 & -0.5 & -4.2 & 11.8 & 16.1 & -1.0 & -3.3 \\
\hline Rio $\mathrm{C}$ & 13.6 & 17.7 & 5.0 & -9.1 & 8.1 & 16.2 & 2.1 & -10.2 & 5.2 & 9.1 & 3.2 & -7.1 & 5.1 & 11.1 & 5.2 & -11.2 & 22.5 & 26.5 & 3.3 & -7.3 & 10.9 & 16.1 & 3.8 & -9.0 \\
\hline
\end{tabular}

*Ranked from highest to lowest in terms of 5-period average percentage of total employment growth rate. 
Table 3: Location Quotients and Hirschman-Herfindahl Index of Brazil’s States, 1981; Ordered from north to south

Note: values higher than 1.5 are in bold, and those lower than 0.5 are in italics.

\begin{tabular}{|c|c|c|c|c|c|c|c|c|c|c|}
\hline State & $\begin{array}{c}\text { Agriculture } \\
\text { and } \\
\text { Fishing }\end{array}$ & Commerce & Construction & $\begin{array}{l}\text { Electricity, } \\
\text { Water and } \\
\text { Gas }\end{array}$ & $\begin{array}{l}\text { Financial } \\
\text { Sector }\end{array}$ & Manufacturing & Mining & Services & $\begin{array}{l}\text { Transportation } \\
\text { and } \\
\text { Communication }\end{array}$ & $\begin{array}{l}\text { Hirschman- } \\
\text { Herfindahl } \\
\text { Index }(\mathrm{HHI})^{*}\end{array}$ \\
\hline Acre & 0.400 & 1.571 & 0.468 & 2.156 & 1.619 & 0.809 & 1.170 & 1.599 & 1.819 & 0.227 \\
\hline Amazonas & 0.296 & 1.797 & 1.020 & 2.021 & 1.019 & 1.453 & 1.255 & 1.161 & 1.381 & 0.194 \\
\hline Amapá & 0.191 & 1.598 & 1.481 & 1.308 & 0.741 & 0.830 & 2.674 & 1.516 & 2.042 & 0.216 \\
\hline Pará & 0.409 & 1.803 & 1.049 & 1.301 & 0.867 & 0.792 & 2.774 & 1.345 & 1.789 & 0.198 \\
\hline Rondônia & 0.445 & 1.911 & 1.149 & 1.800 & 0.603 & 0.754 & 3.184 & 1.202 & 1.969 & 0.186 \\
\hline Roraima & 0.239 & 1.544 & 2.328 & 3.701 & 1.384 & 0.373 & 8.416 & 1.282 & 1.576 & 0.188 \\
\hline Tocantins & 2.351 & 1.756 & 0.194 & 0.179 & 0.003 & 0.010 & 0.040 & 0.023 & 0.444 & 0.614 \\
\hline Alagoas & 1.712 & 0.625 & 0.873 & 0.486 & 0.390 & 0.569 & 0.843 & 0.683 & 0.670 & 0.353 \\
\hline Bahia & 1.710 & 0.841 & 0.757 & 0.811 & 0.513 & 0.446 & 1.426 & 0.674 & 0.656 & 0.351 \\
\hline Ceará & 1.013 & 0.889 & 2.104 & 0.763 & 0.399 & 0.934 & 0.537 & 0.821 & 0.619 & 0.213 \\
\hline Maranhão & 2.086 & 0.628 & 0.594 & 0.740 & 0.229 & 0.227 & 1.006 & 0.535 & 0.511 & 0.479 \\
\hline Paraíba & 1.043 & 0.964 & 2.477 & 0.847 & 0.438 & 0.477 & 1.294 & 0.861 & 0.725 & 0.223 \\
\hline Pernambuco & 1.230 & 1.157 & 0.936 & 1.079 & 0.619 & 0.764 & 0.334 & 0.858 & 0.919 & 0.241 \\
\hline Piauí & 1.629 & 0.585 & 2.209 & 0.486 & 0.340 & 0.247 & 0.494 & 0.575 & 0.542 & 0.339 \\
\hline Rio Grande do Norte & 1.077 & 0.908 & 1.320 & 1.033 & 0.629 & 0.613 & 5.410 & 1.009 & 0.945 & 0.218 \\
\hline Sergipe & 1.358 & 0.651 & 1.140 & 0.929 & 0.426 & 0.606 & 6.714 & 0.776 & 1.166 & 0.256 \\
\hline Distrito Federal & 0.113 & 1.583 & 1.219 & 1.983 & 2.658 & 0.432 & 0.053 & 1.899 & 1.740 & 0.276 \\
\hline Goiás & 1.179 & 1.055 & 0.902 & 0.833 & 0.864 & 0.453 & 1.681 & 1.132 & 0.937 & 0.249 \\
\hline Mato Grosso do Sul & 1.012 & 1.113 & 1.173 & 1.146 & 0.790 & 0.597 & 0.689 & 1.110 & 1.205 & 0.219 \\
\hline Mato Grosso & 1.327 & 1.087 & 0.885 & 1.337 & 0.859 & 0.362 & 5.546 & 0.853 & 1.088 & 0.255 \\
\hline Espírito Santo & 1.417 & 0.798 & 0.982 & 0.669 & 0.732 & 0.656 & 1.511 & 0.793 & 0.985 & 0.275 \\
\hline Minas Gerais & 1.190 & 0.833 & 0.964 & 0.809 & 0.745 & 0.689 & 1.110 & 1.075 & 0.925 & 0.246 \\
\hline Rio de Janeiro & 0.178 & 1.227 & 1.181 & 1.633 & 1.714 & 1.229 & 0.747 & 1.569 & 1.704 & 0.225 \\
\hline São Paulo & 0.371 & 1.167 & 0.917 & 1.006 & 1.679 & 1.864 & 0.365 & 1.168 & 1.130 & 0.207 \\
\hline Paraná & 1.551 & 0.917 & 0.686 & 0.803 & 0.802 & 0.573 & 0.491 & 0.761 & 0.825 & 0.309 \\
\hline Santa Catarina & 1.402 & 0.730 & 0.546 & 1.485 & 0.645 & 1.174 & 1.165 & 0.676 & 0.897 & 0.276 \\
\hline Rio Grande do Sul & 1.190 & 0.894 & 0.797 & 0.994 & 0.872 & 0.983 & 1.128 & 0.909 & 0.889 & 0.237 \\
\hline
\end{tabular}

* $H H I=\sum_{J \notin K} s_{i j}^{2}$ where $s_{\mathrm{ij}}$ is the share in state $i$ of the industry $j$ in local (State) total employment. 


\section{References}

Abreu, M. P. (2008a). The Brazilian economy, 1930-1980. In L. Bethell (Ed.), The Cambridge history of Latin America (Vol. IX) (pp. 283-394). Cambridge, England: Cambridge University Press.

Abreu, M. P. (2008b). The Brazilian economy, 1980-1994. In L. Bethell (Ed.), The Cambridge history of Latin America (Vol. IX) (pp. 395-430). Cambridge, England: Cambridge University Press.

Abreu, M. P., and Werneck, R. L. F. (2008). The Brazilian economy, 1994-2004. In L. Bethell (Ed.), The Cambridge history of Latin America (Vol. IX) (pp. 431-454). Cambridge, England: Cambridge University Press.

Amorim, M.A., and Da Mata, D. (2008). The Cariri region of Ceará and the footwear cluster. Paper presented at Conference 'Trajetórias de Desenvolvimento Local e Regional: Uma comparação entre as Regiões do Nordeste Brasileiro e a Baixa Califórnia, México’, Fortaleza, Brazil.

Andrikopoulos, A., Brox, J., and Carvalho, E. (1990). Shift-share analysis and the potential for predicting regional growth patterns: Some evidence for the region of Quebec, Canada. Growth and Change, 21(1), 1-10.

Anselin, L. (1989). What is special about spatial data? Alternative perspectives on spatial data analysis. Paper prepared for presentation at the Spring 1989 Symposium on Spatial Statistics, Past, Present and Future, Department of Geography, Syracuse University.

Anselin, L. (1995). Local indicators of spatial association - LISA. Geographical Analysis, 27(2), 93-115.

Arcelus, F. (1984). An extension of shift-share analysis. Growth and Change, 15(1), 3-8.

Autant-Bernard, C., Mairesse, J., and Massard, N. (2007). Spatial knowledge diffusion through collaborative networks. Papers in Regional Science, 86(3), 341-350. doi:10.1111/j.1435-5957.2007.00134.x

Barff, R.D., and Knight, P. L. (1988). Dynamic shift-share analysis. Growth and Change, 19(2), 1-10.

Barro, R. J., and Sala-i-Martin, X. (2004). Economic growth. Cambridge, MA: MIT Press.

Bavaud, F. (1998). Models for spatial weights: A systematic look. Geographical Analysis, 30(2), 153-171.

Berzeg, K. (1978). The empirical content of shift-share analysis. Journal of Regional Science, 18(3), 463469.

Berzeg, K. (1984). A note on statistical approaches to shift-share analysis. Journal of Regional Science, 24(2), 277-285.

Biles, J. J. (2003). Using spatial econometric techniques to estimate spatial multipliers: An assessment of regional economic policy in Yuácatan, Mexico. The Review of Regional Studies, 33(2), 121-141.

Bishop, K. C., and Simpson, C. E. (1972). Components of change analysis: Problems of alternative approaches to industrial structure. Regional Studies, 6(1), 59-68.

Blien, U., and Wolf, K. (2002). Regional development of employment in Eastern Germany: An analysis with an econometric analogue to shift-share techniques. Papers in Regional Science, 81(3), 391-414.

Brakman, S., Garretsen, H., and van Marrewijk, C. (2001). An introduction to geographical economics: Trade, location and growth. Cambridge, England: Cambridge University Press.

Brown University (n.d). Spatial analysis with GeoDa: Spatial autocorrelation. Available from Brown University S4 - Spatial Structure in the Social Science website: http://www.s4.brown.edu/

Chahad, J. P. Z., Comune, A. E., and Haddad, E. A. (2002). Shifts in regional employment: An application of the Haynes-Dinc model for Brazil. Paper presented at the European Regional Science Association, Dortmund, Germany.

Cochrane, W., and Poot, J. (2008). Forces of change: A dynamic shift-share and spatial analysis of employment change in New Zealand labour market areas. Studies in Regional Science, 38(1): 51-78.

Daumal, M., and Zignago, S. (2010). Measure and determinants of border effects of Brazilian states. Papers in Regional Science, 89(4). doi:10.1111/j.1435-5957.2009.00265.x

Dinc, M., and Haynes, K. E. (1999). Regional efficiency in the manufacturing sector: Integrated shift share and data development analysis. Economic Development Quarterly, 13(2), 183-199.

Dinc, M., and Haynes, K. (2005). Productivity, international trade and reference area interactions in shiftshare analysis: Some operational notes. Growth and Change, 36(3), 374-394.

Dinc, M., Haynes, K., and Qiangsheng, L. (1998). A comparative evaluation of shift-share models and their extensions. Australasian Journal of Regional Studies, 4(2), 275-302.

Dunn, E.S. (1960). A statistical and analytical technique for regional analysis. Papers of the Regional Science Association, 6(1), 97-112. 
The Economist (2009). Brazil takes off: Now the risk for Latin America's big success story is hubris. The Economist. Nov $12^{\text {th }} 2009$, print edition. http://www.economist.com/node/14845197

Enders, W. T. (1980). Regional disparities in industrial growth in Brazil. Economic Geography, 56(4), 300310.

Esteban-Marquillas, J. M. (1972). A reinterpretation of shift-share analysis. Regional and Urban Economics, 2(3), 249-255.

Fausto, B. (1999). A concise history of Brazil. (A. Brakel, Trans.). Cambridge, England: Cambridge University Press. (Original work published 1998).

Fotopoulos, G., and Spence, N. (1999). Spatial variations of net entry rates of establishments in Greek manufacturing industries: An application of a shift-share ANOVA model. Environment and Planning A, 31(10), 1731-1755.

Fotopoulos, G., Kallioras, D., and Petrakos, G. (2010). Spatial variations of Greek manufacturing employment growth: The effects of specialization and international trade. Papers in Regional Science, 89(1), 109-134.

Gazel, C. R., and Schwer, R. K. (1998). Growth of international exports among the states: Can a modified shift-share analysis explain it? International Regional Science Review, 21(2), 185-204. doi: $10.1177 / 016001769802100205$.

Getis, A. (1991). Spatial interaction and spatial autocorrelation: A cross-product approach. Environment and Planning A 23(9), 1269-1277. doi:10.1068/a231269. Reprinted with permission of PION Limited, London.

Hanham, R. Q., and Banasick, S. (2000). Shift-share analysis and changes in Japanese manufacturing employment. Growth and Change, 31(1), 108-123.

Haynes, K. E., and Dinc, M. (1997). Productivity change in manufacturing regions: A multifactor/shift-share approach. Growth and Change, 28(2), 201-221.

Haynes, K., and Machunda, Z.B. (1987). Considerations in extending shift-share analysis: Note. Growth and Change, 18(2), 69-78.

Hoppes, R. B. (1991). Regional versus industrial shift-share analysis-with help from the Lotus spreadsheet. Economic Development Quarterly, 5(3), 258-267.

IBGE (2010). Brazilian Institute of Geography and Statistics. www.ibge.gov.br.

IPEA (2010). Institute of Applied Economic Research. www.ipea.gov.br.

Keil, S. R. (1992). On the value of homotheticity in the shift-share framework. Growth and Change, 23(4), 469-493.

Knudsen, D. C. (2000). Shift-share analysis: Further examination of models for the description of economic change. Socio-Economic Planning Sciences, 34(3), 177-198.

Knudsen, D. C., and Barff, R. (1991). Shift-share analysis as a linear model. Environment and Planning A, 23(3), 421-431.

Krugman, P. (1991). Increasing returns and economic geography. Journal of Political Economy, 99(3), 483499.

Le Gallo, J., and Kamarianakis, Y. (2010). The evolution of regional productivity disparities in the European Union from 1975 to 2002: A combination of shift-share and spatial econometrics. Regional Studies, 117, iFirst article. doi: 10.1080/00343400903234662.

LeSage, J., and Pace, R. K. (2009). Introduction to spatial econometrics. London: CRC Press.

Lobo, E. M. L. (1996). Brazil since 1889. In B. A. Tenenbaum (Ed.). Encyclopedia of Latin American history and culture (pp. 424-432). New York: Simon and Schuster Macmillan.

Loveridge, S. (1995). A practical approach to shift-share analysis. Journal of the Community Development Society, 26(1), 111-124.

Loveridge, S., and Selting, A. C. (1998). A review and comparison of shift-share identities. International Regional Science Review. 21(1), 37-58.

Markusen, A. R., Noponen, H., and Driessen, K. (1991). International trade, productivity, and U.S. regional job growth: A shift-share interpretation. International Regional Science Review, 14(1), 15-39.

Matlaba, V. J. et al. (2010). Agglomeration externalities and 1981-2006 regional growth in Brazil. Paper presented at the $57^{\text {th }}$ Annual North American Meetings of the Regional Science Association International (10-13, November), Denver, Colorado, the United States.

Matlaba, V. J. (2012). Regional socio-economic transformation in Brazil. PhD Dissertation. Hamilton: University of Waikato. 
Mayor, M., and López, A. J. (2008). Spatial shift-share analysis versus spatial filtering: An application to Spanish employment data. Empirical Economics, 34, 123-142. doi: 10.1007/s00181-007-0167-9.

McCann, P. (2001). Urban and regional economics. New York: Oxford University Press.

McDonough, C. C., and Sihag, B. S. (1991). The incorporation of multiple bases into shift-share analysis. Growth and Change, 22(1), 1-9.

Mitchell, W., Myers, J., and Juniper, J. (2005). Extending shift-share analysis to account for spatial effects: A study using Australian census data. Working Paper \#05-19, Centre of Full Employment and Equity, University of Newcastle, Callaghan, Australia.

Nazara, S., and Hewings, G. J. D. (2004). Spatial structure and taxonomy decomposition in shift-share analysis. Growth and Change, 35(4), 476-490.

Newton, H. J. (Ed.) (2001). Stata technical Bulletin: A publication to promote communication among Stata users. Texas, USA: Department of Statistics, Texas A and M University.

Nogueira, C. A. G., and Lopes, D. A. F. (2008). Employment growth in Ceará: A shift-share analysis (20002005). Paper presented at Congress of The Regional Science Association International, São Paulo, Brazil.

Noponen, H., Markusen, A. R., and Driessen, K. (1998). International trade and shift-share analysis: A response to Dinc and Haynes. Economic Development Quarterly, 11(4), 344-350.

Pisati, M. (2010). Spatreg, spatlsa, spatwmat: Stata module to estimate the spatial regression model, local indicators of spatial association, and spatial weight matrix. www.stata.com.

Ray, M.A., and Harvey, J. T. (1995). Employment changes in the European Economic Community: A shiftshare analysis. Review of Regional Studies, 25(1), 97-110.

Resende, G. M. (2011). Multiple dimensions of regional economic growth: The Brazilian case, 1991-2000. Papers in Regional Science, 90(3). doi:10.1111/j.1435-5957.2010.00336.x

Road Transportation Information website of The Ministry of Transportation of Brazil: http://www.transportes.gov.br/bit/inrodo.htm. <Accessed March, 2009>.

Rolim, C. (2008). Decomposing the GDP growth of the great Brazilian regions: Dynamic shift-share on recent Brazilian economic cycles. Paper presented at Congress of The Regional Science Association International, São Paulo, Brazil.

Selting, A. C., and Loveridge, S. (1994). Testing dynamic shift-share, Regional Science Perspectives. 24(1), 23-41.

Shields, M. (2003). Using employment data to better understand your local economy: Shift share analysis helps identify local growth engines. In Understanding Economic Change in Your Community Series, Center for Economic and Community Development at Penn State. http://cecd.aers.psu.edu/ <Accessed August, 2010>.

Yasin, M., Alavi, J., Sobral, F., and Lisboa, J. (2010). A Shift-share analysis approach to understanding the dynamic of the Portuguese tourism market. Journal of Travel and Tourism Marketing, 17(4), 11-22. 